$11-2002$

\title{
Primary Dendrite Distribution and Disorder During Directional Solidification of $\mathrm{Pb}-\mathrm{Sb}$ Alloys
}

Jun Hui

Eqllovythis sandeadditionstylyorks at: https://engagedscholarship.csuohio.edu/encbe_facpub

Part of the Materials Science and Engineering Commons

R. Tiwari

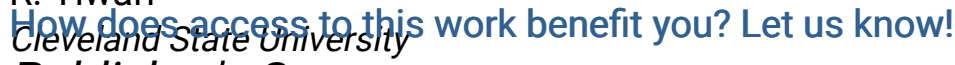

Publisher's Statement

Xofyttight 2002 ASM International. This paper was published in Metallurgical and Materials Cleveland State University

Transactions A: Physical Metallurgy and Materials Science, Vol. 33, Issue 11, pp. 3499-3510 and

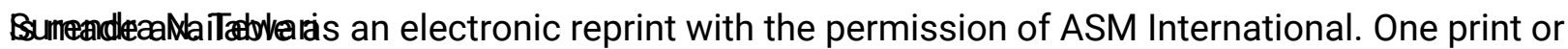

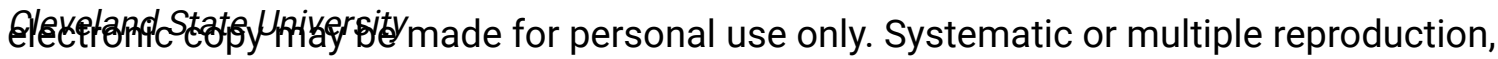

Ristfibetijon to multiple locations via electronic or other means, duplications of any material in

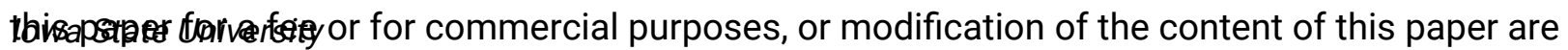
prohibited.

Available on publisher's site at: http://hts.asminternational.org/portal/site/www/AsmStore/ ProductDetails/?vgnextoid=b4159163991e5210VgnVCM100000621e010aRCRD.

\section{Original Citation}

Hui, J., Tiwari, R., Wu, X., Tewari, S.N., \& Trivedi, R. (2002). Primary Dendrite Distribution and Disorder During Directional Solidification of Pb-Sb Alloys. Metallurgical and Materials Transactions A: Physical Metallurgy and Materials Science 33, 3499-3510.

\section{Repository Citation}

Hui, Jun; Tiwari, R.; Wu, X.; Tewari, Surendra N.; and Trivedi, R., "Primary Dendrite Distribution and Disorder During Directional Solidification of Pb-Sb Alloys" (2002). Chemical \& Biomedical Engineering Faculty Publications. 17. https://engagedscholarship.csuohio.edu/encbe_facpub/17

This Article is brought to you for free and open access by the Chemical \& Biomedical Engineering Department at EngagedScholarship@CSU. It has been accepted for inclusion in Chemical \& Biomedical Engineering Faculty Publications by an authorized administrator of EngagedScholarship@CSU. For more information, please contact library.es@csuohio.edu. 


\title{
Primary Dendrite Distribution and Disorder during Directional Solidification of $\mathrm{Pb}-\mathrm{Sb}$ Alloys
}

\author{
JUN HUI, R. TIWARI, X. WU, S.N. TEWARI, and R. TRIVEDI
}

\begin{abstract}
$\mathrm{Pb}-2.2$ wt pct $\mathrm{Sb}$ and $\mathrm{Pb}-5.8$ wt pct $\mathrm{Sb}$ alloys have been directionally solidified from a single-crystal seed with its [100] orientation parallel to the growth direction, to examine the primary dendrite distribution and disorder of the dendrite arrays. The dendrite distribution and ordering have been investigated using analysis techniques such as the Gauss-amplitude fit to the frequency distribution of nearest and higher-order spacings, minimum spanning tree (MST), Voronoi polygon, and Fourier transform (FT) of the dendrite centers. Since the arrangement of dendrites is driven by the requirement to accommodate side-branch growth along the $\langle 100\rangle$ directions, the FT images of the fully developed dendrite centers contain spots which indicate this preferred alignment. A directional solidification distance of about three mushy-zone lengths is sufficient to ensure a steady-state dendritic array, in terms of reaching a constant mean primary spacing. However, local dendrite ordering continues throughout the directional solidification process. The interdendritic convection not only decreases the mean primary spacing, it also makes the dendrite array more disordered and reduces the ratio of the upper and lower spacing limits, as defined by the largest 5 pct and the smallest 5 pct of the population.
\end{abstract}

\section{INTRODUCTION}

IN order to achieve uniformity in the mechanical properties of materials, it is important to avoid any inhomogeneity in the spatial distribution of dendritic microstructures that are formed during solidification processing. This is especially true in directionally solidified superalloy gas turbine engine components, such as turbine blades and vanes. An extensive body of literature ${ }^{[1-5]}$ exists on the dependence of the average primary spacing on the composition, growth speed, and thermal gradients, for the dendritic morphologies. The average primary dendrite spacing has generally been measured as $\sqrt{A /(N-1)}$, where $N$ is the number of dendrites in a given area of $A$ on a cross section that is transverse to the growth direction. This technique inherently assumes a square distribution of dendrites. However, an analysis of the nearest and higher-order spacing distribution of dendrites indicated their arrangement to be closer to a hexagonal pattern. ${ }^{[6]}$ While cellular arrays have been extensively studied for their spacing distribution during initial transient growth and during steady-state growth using analytical techniques such as minimum spanning trees (MSTs) ${ }^{[7,8,9]}$ and Voronoi polygons, ${ }^{[7,8,9]}$ similar studies for dendritic arrays have not been carried out.

The purpose of this study was to examine the influence of interdendritic convection on the distribution of primary dendrites during initial transient growth and during the subsequent steady-state directional solidification of binary metallic alloys. During directional solidification of metallic alloys, with the melt on top and solid below, the thermal profile is expected to cause stability against convection. However, the solutal profile in the mushy zone and in the

JUN HUI and R. TIWARI, Graduate Students, X. WU, Research Associate, and S.N. TEWARI, Professor, are with the Chemical Engineering Department, Cleveland State University, Cleveland, OH 46115. Contact e-mail: s.tewari@csuohio.edu R. TRIVEDI, Professor, is with the Department of Materials Science and Engineering, Iowa State University, Ames, IA 50011.

Manuscript submitted January 31, 2002. overlying melt immediately ahead of the dendritic array would be expected to be stable only if the solute enrichment increases the melt density, as is the case with the $\mathrm{Al}-\mathrm{Cu}$ alloy. In the hypoeutectic $\mathrm{Pb}$-Sb alloys, the solute enrichment decreases the melt density, which causes convection in the mushy zone. ${ }^{[10]}$ Two alloy compositions, $\mathrm{Pb}-5.8$ wt pct $\mathrm{Sb}$ and $\mathrm{Pb}-2.2$ wt pct $\mathrm{Sb}$, were selected to achieve varying degrees of thermosolutal convection in the mushy zone. The dendritic array for the $\mathrm{Pb}-5.8 \mathrm{wt}$ pct $\mathrm{Sb}$ alloy is expected to be more permeable than that for the $\mathrm{Pb}-2.2 \mathrm{wt}$ pct $\mathrm{Sb}$ for similar growth conditions, because of its larger interdendritic liquid fraction (the interdendritic eutectic volume fraction is approximately 0.38 for the $\mathrm{Pb}-5.8 \mathrm{wt}$ pct $\mathrm{Sb}$, vs 0.09 for the $\mathrm{Pb}-2.2$ wt pct $\mathrm{Sb}$ ). Therefore, the $5.8 \mathrm{wt}$ pct $\mathrm{Sb}$ alloy would be subject to more interdendritic convection than the 2.2 wt pet $\mathrm{Sb}$ alloy.

Since the dendritic morphologies are known to depend on the crystallographic growth direction during directional solidification, ${ }^{[11]}$ the experimentally observed primary spacing distribution would contain considerable scatter associated with the grain multiplicity and grain boundaries. Therefore, we have examined samples that were directionally solidified along the [100] direction using a single-crystal seed, to yield morphologies that were near the cell-to-dendrite transition, dendritic (immediately after evolution of side branches), and fully developed dendritic (well developed side branches). The distribution of the dendrite centers on the transverse sections has been studied by using MSTs, Voronoi polygons, Gauss-amplitude analysis of the nearest and higher-order primary spacings, and Fourier transforms (FTs).

\section{EXPERIMENTAL PROCEDURE}

\section{A. Alloy Preparation and Directional Solidification}

About 24- to 30-cm-long $\mathrm{Pb}-\mathrm{Sb}$ feedstock samples were obtained by induction melting a charge ( $\mathrm{Pb} 99.99$ wt pct purity and Sb 99.999 wt pct purity) under an ultrahigh-purity 
argon atmosphere in a graphite crucible and pushing the melt into evacuated quartz tubes $(0.6-\mathrm{cm}$ i.d.) with the help of argon pressure. The cast $\mathrm{Pb}-2.2$ wt pct $\mathrm{Sb}$ or $\mathrm{Pb}-5.8 \mathrm{wt}$ pct $\mathrm{Sb}$ feedstock cylinders were extracted and placed into a quartz directional solidification ampoule (0.7-cm i.d., 61$\mathrm{cm}$ long) on top of a pure lead single-crystal seed. The [100] crystallographic orientation of the seed was parallel to the axis of the ampoule. After remelting about $1 \mathrm{~cm}$ of the seed, the sample was directionally solidified in ultrahigh-purity argon at $10 \mu \mathrm{m} \mathrm{s}^{-1}$ to obtain a seed about $15-\mathrm{cm}$ long. A $4.5-\mathrm{cm}$ long piece from this single crystal was used as a seed for all the $\mathrm{Pb}-2.2$ wt pct $\mathrm{Sb}$ and $\mathrm{Pb}-5.8$ wt pct $\mathrm{Sb}$ specimens directionally solidified in this study. Growth speeds of 3,10, 30, 70 and $156 \mu \mathrm{m} \mathrm{s}^{-1}$ have been used, with the thermal gradient in the liquid at the liquid-solid interface being $40 \mathrm{~K} \mathrm{~cm}^{-1}$. After $9 \mathrm{~cm}$ of directional solidification (initial melt-column length at the onset of directional solidification was about $18 \mathrm{~cm}$ ), the ampoule was quickly pulled from the furnace, and the melt column was quenched by spraying water on the ampoule surface.

\section{B. Metallography}

Longitudinal (parallel to the alloy growth direction) and transverse microstructures were observed by standard polishing and optical metallography techniques. An etchant made up of $60 \mathrm{~mL}$ acetic acid and $40 \mathrm{~mL}$ hydrogen peroxide (30 pct) was used to provide suitable contrast for electronic image capture of $\mathrm{Pb}-\mathrm{Sb}$ alloys.

\section{RESULTS}

\section{A. Typical Microstructures}

Figure 1 shows typical transverse microstructures of the directionally solidified $\mathrm{Pb}-5.8$ wt pct $\mathrm{Sb}$ and $\mathrm{Pb}-2.2$ wt pct $\mathrm{Sb}$. All these samples were grown from the [100] orientation single-crystal seed and were quenched after about $9 \mathrm{~cm}$ of growth. The transverse sections represent microstructures within about $300 \mu \mathrm{m}$ of the quenched dendrite tips. Typical microstructures of the $\mathrm{Pb}-5.8$ wt pet $\mathrm{Sb}$ alloy grown at 40 $\mathrm{K} \mathrm{cm}^{-1}$ are shown in Figure 1(a). A typical higher-magnification view is presented in the inset of these figures. The dark interdendritic regions in the microstructure correspond to the liquid present in the mushy zone at the time of quench. At a growth speed of $3 \mu \mathrm{m} \mathrm{s}^{-1}$, this alloy shows interior "channel segregates" in the middle of the sample cross section (Figure 1(a-i)). This is an indication of extensive convection. ${ }^{[12]}$ Figure 1(a-ii) shows the transverse microstructure of the $\mathrm{Pb}-5.8 \mathrm{wt}$ pct $\mathrm{Sb}$ alloy solidified at $10 \mu \mathrm{m} \mathrm{s}^{-1}$. There is no channel segregate in this sample, but the distribution of dendrites or the volume fraction of interdendritic liquid is not uniform across the entire sample cross section. A higher volume fraction of interdendritic liquid is evident in the middle of the sample as compared with the rest of the sample cross section. A higher growth speed causes more side branching and produces tertiary and higher-level side branches, as seen in the $\mathrm{Pb}-5.8 \mathrm{wt}$ pct $\mathrm{Sb}$ sample grown at $70 \mu \mathrm{m} \mathrm{s}^{-1}$ (Figure 1(a-iii)). In addition, the distribution of dendrites appears to be more uniform at $70 \mu \mathrm{m} \mathrm{s}^{-1}$ as compared with 3 or $10 \mu \mathrm{m} \mathrm{s}^{-1}$. Interior channel segregates were not observed in this alloy at solidification speeds of
10 to $157 \mu \mathrm{m} \mathrm{s}^{-1}$. For a [100]-oriented single-crystal dendritically grown sample, one would expect the side branches to be aligned across the entire sample cross section. ${ }^{[11]}$ However, small-angle grain boundaries, invariably present in the sample, would introduce some deviation from such an alignment, as is present in Figure 1(a-iii).

Figure 1(b) shows a typical microstructure in $\mathrm{Pb}-2.2 \mathrm{wt}$ pct $\mathrm{Sb}$ solidified at a thermal gradient of $40 \mathrm{~K} \mathrm{~cm}^{-1}$ and a growth speed of $70 \mu \mathrm{m} \mathrm{s}^{-1}$. As mentioned earlier, the interdendritic liquid volume fraction is less in this alloy as compared with the $\mathrm{Pb}-5.8$ wt pct $\mathrm{Sb}$ alloy. This is evident by comparing the transverse microstructures of the two alloys grown under identical growth conditions $\left(40 \mathrm{~K} \mathrm{~cm}^{-1}\right.$ and $70 \mu \mathrm{m} \mathrm{s}^{-1}$ ): refer to the insets of Figure 1 (a-iii) for $\mathrm{Pb}-5.8$ wt pet $\mathrm{Sb}$ and to Figure 1(b) for $\mathrm{Pb}-2.2$ wt pct $\mathrm{Sb}$. For the growth speeds examined in this study ( 3 to $157 \mu \mathrm{m} \mathrm{s}^{-1}$ ), the $\mathrm{Pb}-2.2$ wt pct $\mathrm{Sb}$ alloy did not show any channel segregates.

\section{B. Typical Microstructural Analyses used in this Study}

Figure 2 uses the $\mathrm{Pb}-5.8 \mathrm{wt}$ pct $\mathrm{Sb}$ alloy sample that was directionally solidified at $10 \mu \mathrm{m} \mathrm{s}^{-1}$ with a thermal gradient of $40 \mathrm{~K} \mathrm{~cm}^{-1}$ as an example (transverse microstructure shown in Figure 1(a-ii), in order to illustrate the typical microstructural analyses carried out in this study. In order to obtain good statistics, all the dendrites on all the sample cross sections (varying from 500 to 1500) were included in these analyses. Since various analytical techniques have already been described in detail, ${ }^{[9]}$ only a brief explanation of these techniques will be presented here. The center of mass of the individual dendrite has been selected as its characteristic representation.

Figure 2(a) shows the distribution of the center of mass of each dendrite. The $X-Y$ coordinates of the dendrite centers were obtained by manually locating them on the magnified images of each dendrite, since this method was more accurate $^{[9]}$ than using automated image-analysis software.

Figure 2(b) shows the corresponding MST, ${ }^{[7,8,9]}$ which represents the shortest total length of the branches in order to connect all the nodes in Figure 2(a). The mean values of the branch lengths $\left(m^{*}\right)$ and their standard deviation $\left(\sigma^{*}\right)$ obtained from the MSTs have been used to provide a statistical measure of the nearest-neighbor distribution for the cellular microstructures in $\mathrm{Pb}-\mathrm{T} 1,{ }^{[7]} \mathrm{Pb}-\mathrm{Sb},{ }^{[9]}$ and Scn-acetone ${ }^{[8]}$ alloys. The $m^{*}$ and $\sigma^{*}$ parameters have been normalized by dividing them by the square root of the average dendrite surface area $(\langle S\rangle)$ to yield $m$ and $\sigma$, where

$$
m=\frac{m^{*}}{\sqrt{\langle S\rangle}} \frac{N-1}{N}
$$

and

$$
\sigma=\frac{\sigma^{*}}{\sqrt{\langle S\rangle}} \frac{N-1}{N}
$$

Dussert and co-workers ${ }^{[13]}$ showed that $m$ vs $\sigma$ plots can be used to compare arrangements with different nearestneighbor spacings. Figure 2(b) also clearly shows the presence of nonuniformity across the sample cross section.

Figure 2(c) shows the frequency distribution of the branch lengths corresponding to the MST shown in Figure 2(b) and a Gaussian fit through the data, where the frequency $(F)$ is given by $F=A_{0} \exp \left(-0.5\left(\left(X-A_{1}\right) / A_{2}\right)^{2}\right)$. The three 

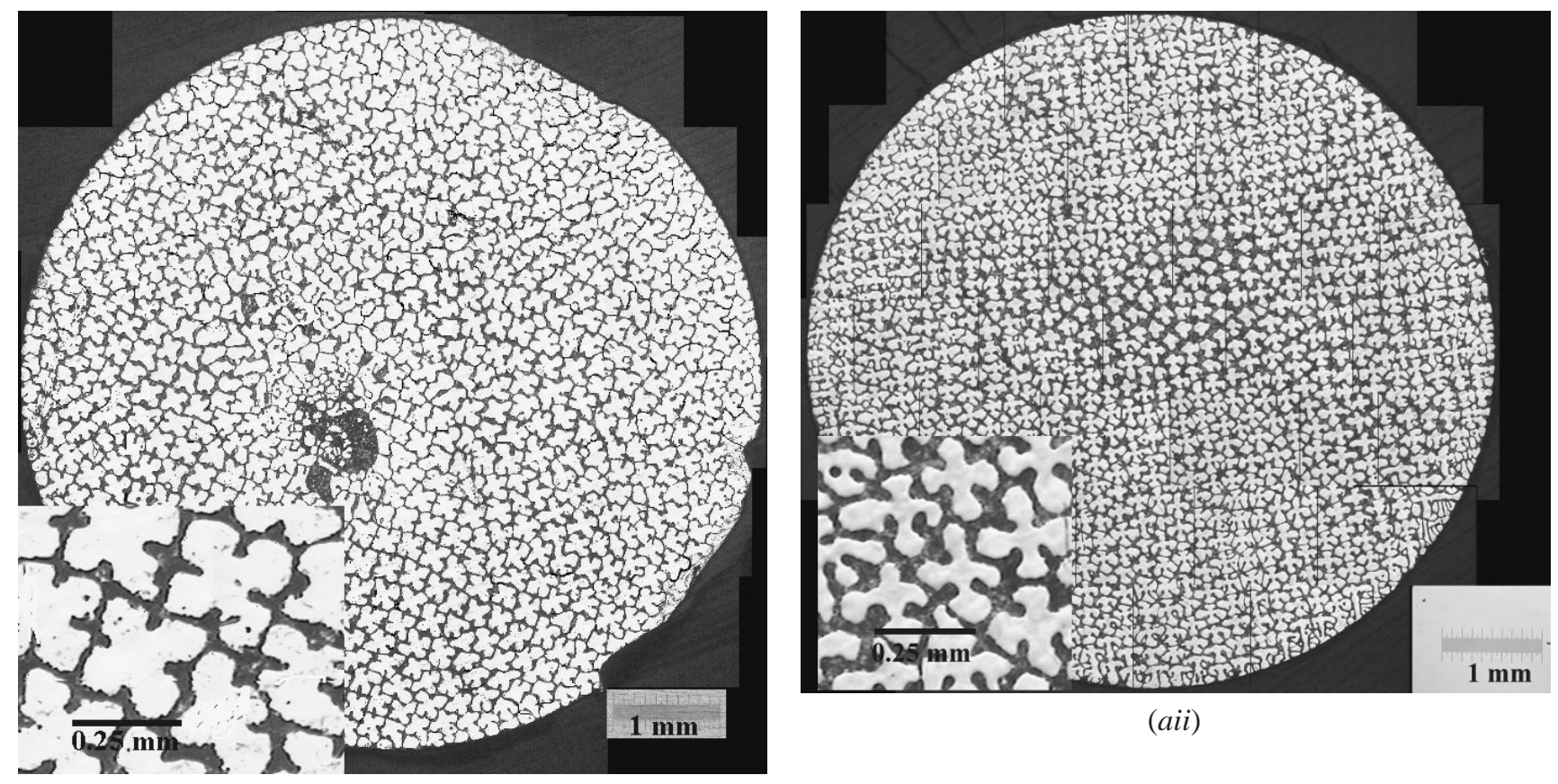

(ai)

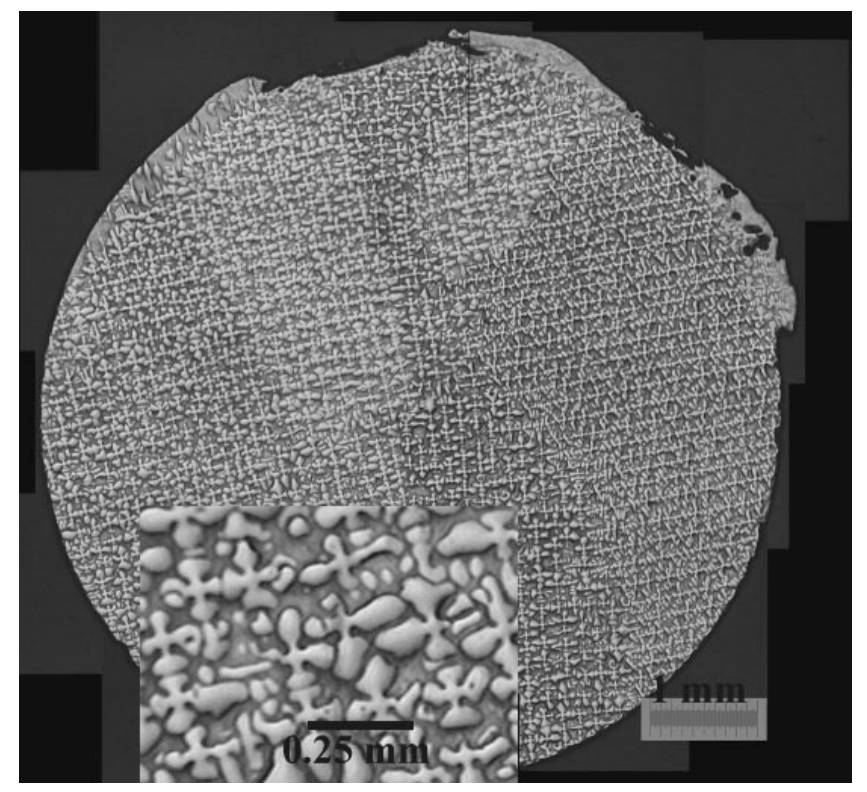

(aiii)

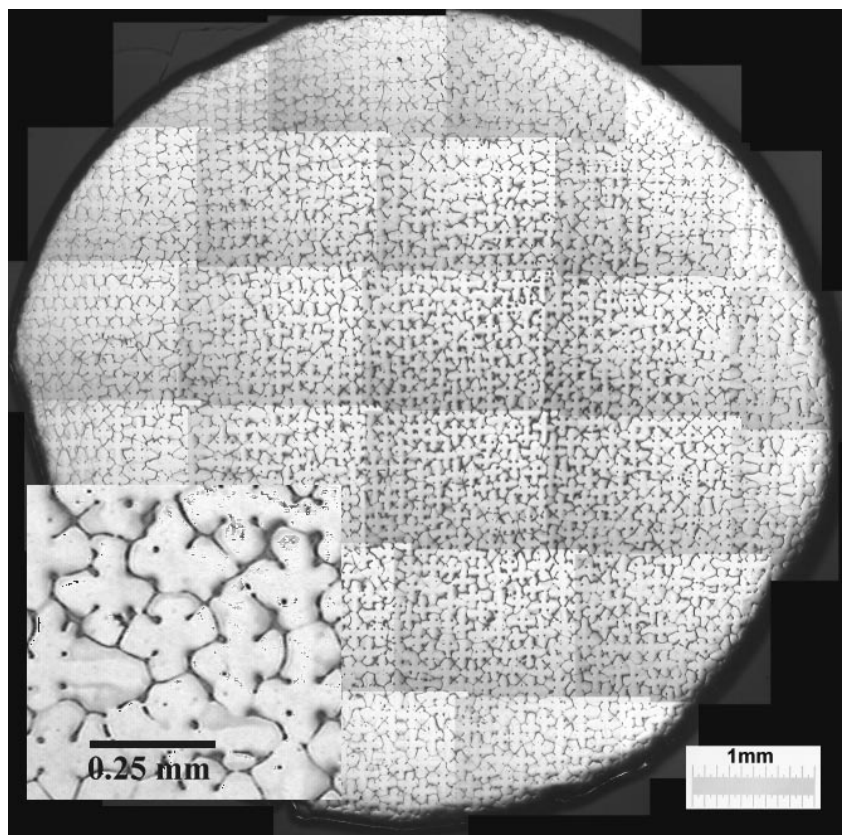

(b)

Fig. 1-Typical dendritic microstructures of directionally solidified Pb-Sb alloys. (a) Lead dendrites in Pb-5.8 wt pct $\mathrm{Sb}$ grown at $40 \mathrm{~K}_{\mathrm{cm}}{ }^{-1}$ with growth speed of (i) 3, (ii) 10, and (iii) $70 \mu \mathrm{m} \mathrm{s}^{-1}$. (b) Lead dendrites in Pb-2.2 wt pet Sb grown at $40 \mathrm{~K} \mathrm{~cm}^{-1}$ with a growth speed of $30 \mu \mathrm{m} \mathrm{s}{ }^{-1}$

parameters for this peak are the amplitude $\left(A_{0}=11.3\right)$, center position $\left(A_{1}=192.1\right)$, and the peak-width parameter $\left(A_{2}=20.0\right)$. The experimentally determined branch-length distribution shows a good fit to the normal distribution. For this sample, the $r^{2}$ parameter, which describes the degree of Gaussian fit, is 0.99 . Let us recall that $A_{1}$ is same as the mean branch length $\left(m^{*}\right)$ and $A_{2}$ is the standard deviation $\left(\sigma^{*}\right)$. The nondimensionalized MST parameters for this sample are $m=0.92$ and $\sigma=0.09$. In this article, we have used the MST branch-length distributions to represent the distribution of primary dendrite spacings.
Figure 2(d) shows the Voronoi polygons corresponding to the dendrite-center distribution in Figure 2(a). Only a portion of the sample cross section is shown here, for the sake of the clarity of the presentation. Voronoi tessellation is a tiling of space where each tile represents the space closest to a particular point. ${ }^{[14]}$ The numbers shown within each polygon indicate the corresponding number of nearest neighbors to each dendrite center. The relative frequency distribution of the number of nearest neighbors obtained from these Voronoi polygons is shown in Figure 2(e). It has an excellent fit to a Gaussian curve, the $r^{2}$ parameter 

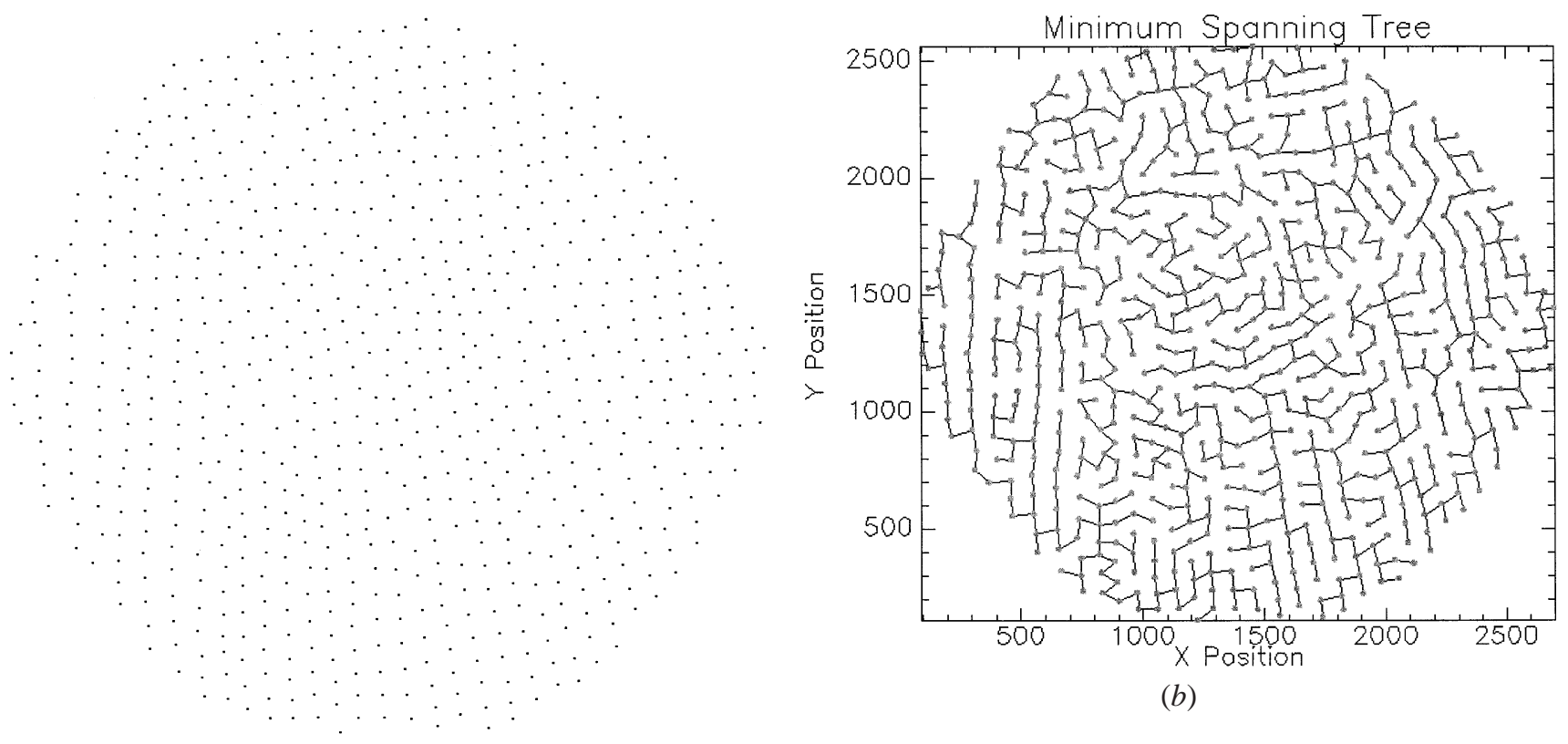

(a)

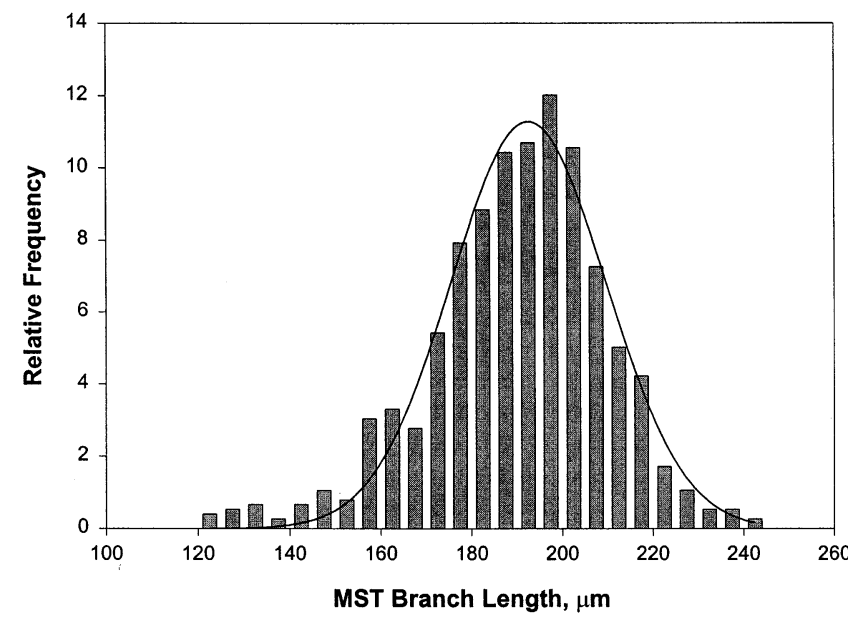

(c)

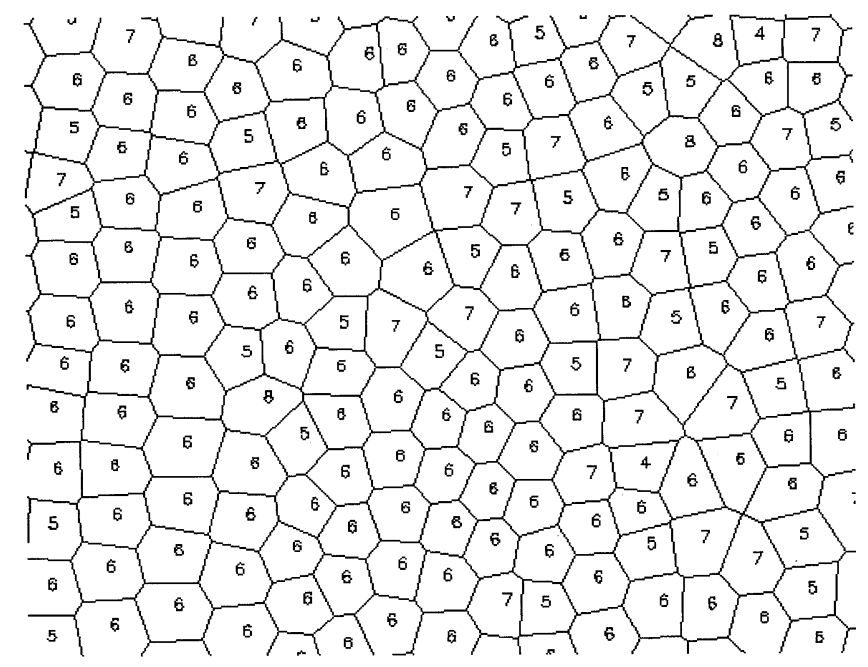

$(d)$

Fig. 2-Typical microstructural analyses illustrated for a Pb-5.8 wt pct Sb alloy sample grown at $10 \mu \mathrm{m} \mathrm{s}^{-1}$ with a thermal gradient of $40 \mathrm{~K} \mathrm{~cm}^{-1}$. $(a)$ Hand-drawn centers of mass of dendrites. (b) Minimum spanning tree based on (a). (c) Frequency distribution of the branch lengths obtained from the minimum spanning tree. $(d)$ Voronoi polygons. Number of nearest neighbors is indicated for each polygon. (e) Relative frequency distribution of the number of nearest neighbors. $(f)$ Fourier transform of the dendrite distribution (FT).

being 0.99 . For the corresponding peak parameters, $A_{0}$, the amplitude, is $62.8 ; A_{1}$, the center position, is 5.96; and $A_{2}$, the width, is 0.62 . It is evident that the six-sided polygons are dominant. However, they still constitute only 63 pct of the population. This is in agreement with earlier observations. ${ }^{[6]}$

The FT of the image containing the dendrite centers can be used to analyze the disorder of the dendritic arrays in a manner similar to that used for examining the cellular arrays. ${ }^{[9]}$ We have transformed the FT images such that distance from the center in an FT image is directly proportional to the frequency, i.e., the intensity (power-spectrum magnitude) corresponding to the highest frequency appears closest to the center in the FT image. Figure 2(f) shows the FT image corresponding to the dendrite-center distribu- tion in Figure 2(a). Figure 2(f) shows some spots appearing to emerge from one diffused broad ring. The FT images obtained from the cellular arrays also showed a broad diffused ring pattern indicating the absence of any longrange order in the distribution of cells. ${ }^{[9]}$ However, unlike the FT images from the dendritic arrays, the cellular array did not contain any spots. This suggests that the cellular and dendritic arrays both have a dominant nearest-neighbor ordering. However, the cellular ordering does not have any directionality associated with it. The crystallographic nature of the side branching in the dendrites influences their nearest-neighbor ordering and introduces directionality in their arrangement, resulting in the several week spots appearing on the broad ring pattern in the FT image (Figure 2(f)). 


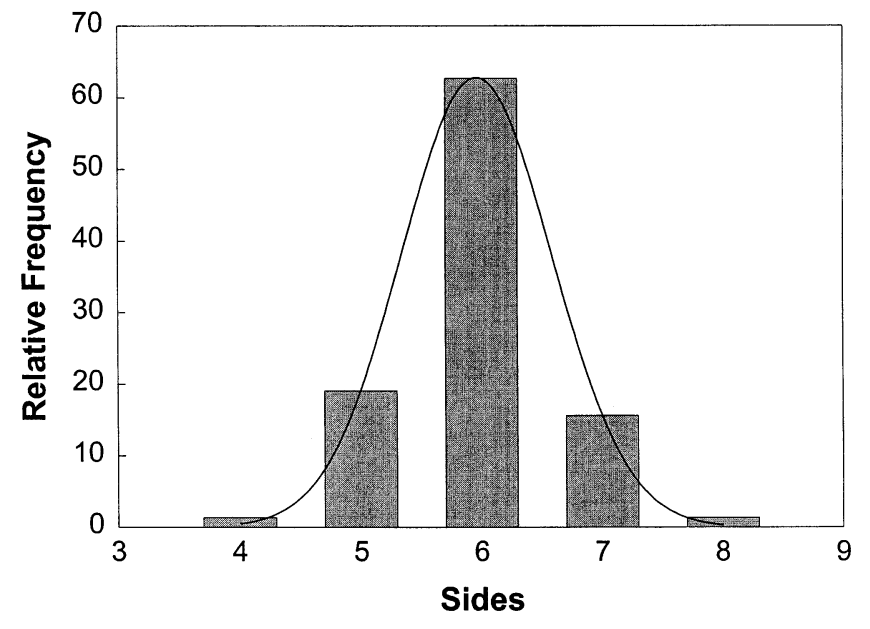

(e)

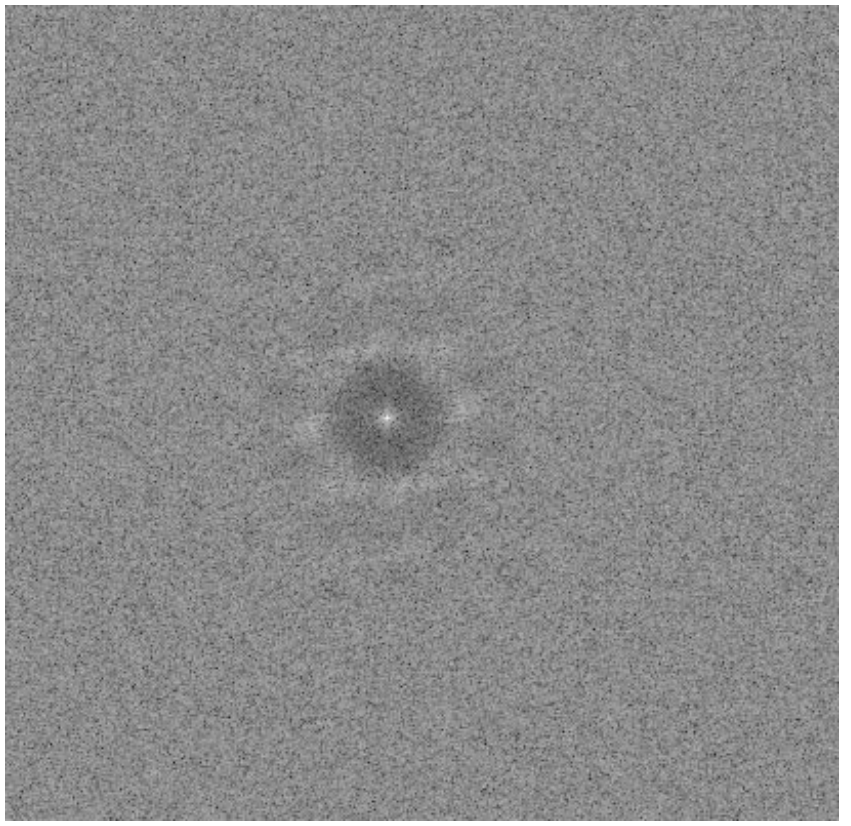

$(f)$

Fig. 2-Continued Typical microstructural analyses illustrated for a Pb-5.8 wt pct Sb alloy sample grown at $10 \mu \mathrm{m} \mathrm{s}^{-1}$ with a thermal gradient of $40 \mathrm{~K}$ $\mathrm{cm}^{-1}$. (a) Hand-drawn centers of mass of dendrites. (b) Minimum spanning tree based on (a). (c) Frequency distribution of the branch lengths obtained from the minimum spanning tree. $(d)$ Voronoi polygons. Number of nearest neighbors is indicated for each polygon. $(e)$ Relative frequency distribution of the number of nearest neighbors. $(f)$ Fourier transform of the dendrite distribution (FT).

\section{Directional Solidification Distance Required to Achieve Steady-State Growth}

In this section, we will examine the directional solidification length necessary to ensure a steady-state growth in terms of achieving a constant mean primary dendrite spacing. Figure 3(a) shows the variation in the mean primary dendrite spacing along the directional solidification length of a $\mathrm{Pb}$ $5.8 \mathrm{wt}$ pet $\mathrm{Sb}$ alloy which was solidified at $3 \mu \mathrm{m} \mathrm{s}^{-1}$ and $40 \mathrm{~K} \mathrm{~cm}^{-1}$. The error bars indicate a standard deviation of \pm 1 . After an increase during the initial two centimeters of directional solidification, the primary dendrite spacing becomes nearly constant, at about $204 \mu \mathrm{m}$. Assuming that the tip of the dendrite array is approximately at the liquidus temperature of the alloy and the base of the mushy zone is at the eutectic temperature, the mushy-zone length for this growth condition is expected to be approximately $0.9 \mathrm{~cm}$. This figure indicates that a solidification distance of $3 \mathrm{~cm}$, approximately three mushy zone lengths, is sufficient to ensure a steady-state distribution of primary dendrites, as defined by their average spacing. Figures 3(b) and (c) show that this observation is also valid at higher growth speeds of 10 and $30 \mu \mathrm{m} \mathrm{s}^{-1}$.

\section{Ordering in the Dendrite Distribution during Directional Solidification}

Although steady-state growth in terms of the mean primary spacing is achieved after a solidification distance of approximately three mushy zone lengths, as shown subsequently, a continued ordering in the distribution of dendrites occurs throughout the directional solidification length, especially in the absence of severe interdendritic convection.

\section{Frequency distribution of number of nearest neighbors}

Figure 4 shows the variation in the relative frequency distribution of the number of nearest neighbors as a function of solidification distance in the $\mathrm{Pb}-5.8 \mathrm{wt}$ pct $\mathrm{Sb}$ alloy samples directionally solidified at 3 and $10 \mu \mathrm{m} \mathrm{s}^{-1}$. These two growth conditions have been selected to illustrate the influence of convection on the ordering of dendrites during directional solidification. The $3 \mu \mathrm{m} \mathrm{s}^{-1}$ sample represents a growth condition with extensive convection present during growth, as evidenced by the presence of channel segregates in the microstructure (Figure $1\left(\mathrm{a}_{\mathrm{i}}\right)$ ). As mentioned earlier, channel segregates were not observed at the higher growth speed of $10 \mu \mathrm{m} \mathrm{s}^{-1}$. Figure 4(a) shows that the Voronoi polygon parameter $A_{1}$, indicating the most probable number of nearest neighbors, does not change along the directional solidification length for the $3 \mu \mathrm{m} \mathrm{s}^{-1}$ sample. However, the sample grown at $10 \mu \mathrm{m} \mathrm{s}^{-1}$ shows that the most predominant nearest-neighbor number increases and becomes closer to six with increasing solidification distance.

This continued ordering along the directional solidification length results in a systematic decrease in the peak-width parameter $A_{2}$ for the sample grown at $10 \mu \mathrm{m} \mathrm{s}^{-1}$, as seen in Figure 4(b). Extensive convection in the mushy zone does not allow this ordering to occur in the $3 \mu \mathrm{m} \mathrm{s}^{-1}$ sample.

2. Variation in the $m$ - $\sigma$ parameter along the directional solidification length

Figure 5 shows the variation in the $m$ and $\sigma$ parameters along the directional solidification length for the previously described two $\mathrm{Pb}-5.8$ wt pet $\mathrm{Sb}$ samples grown at a thermal gradient of $40 \mathrm{~K} \mathrm{~cm}^{-1}$ at 3 and $10 \mu \mathrm{m} \mathrm{s}^{-1}$. The arrows correspond to the increasing directional solidification length. The dotted straight line indicates the $m-\sigma$ variation for a 


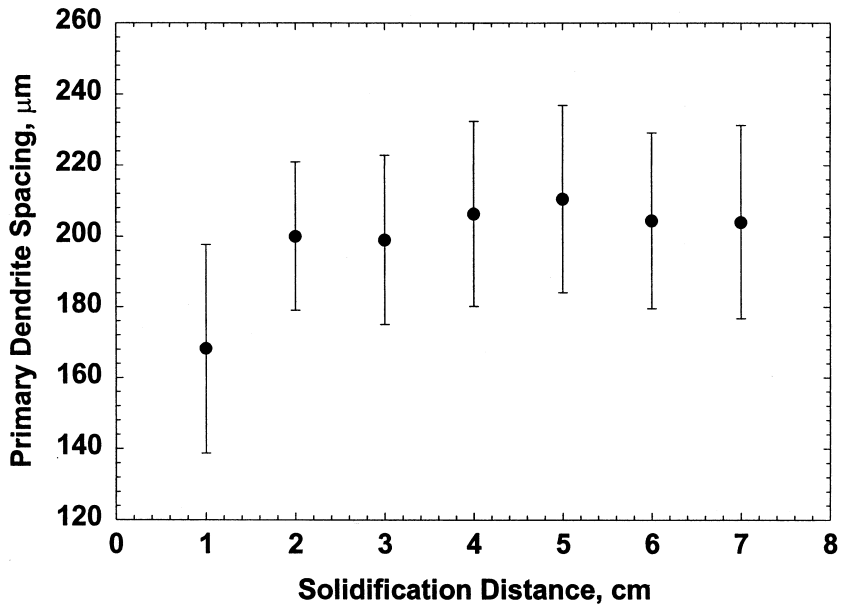

(a)

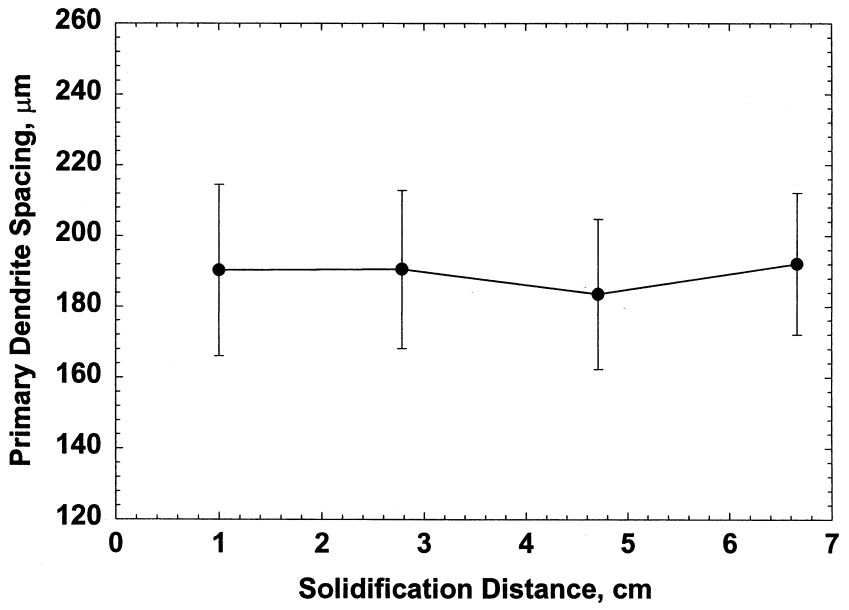

(b)

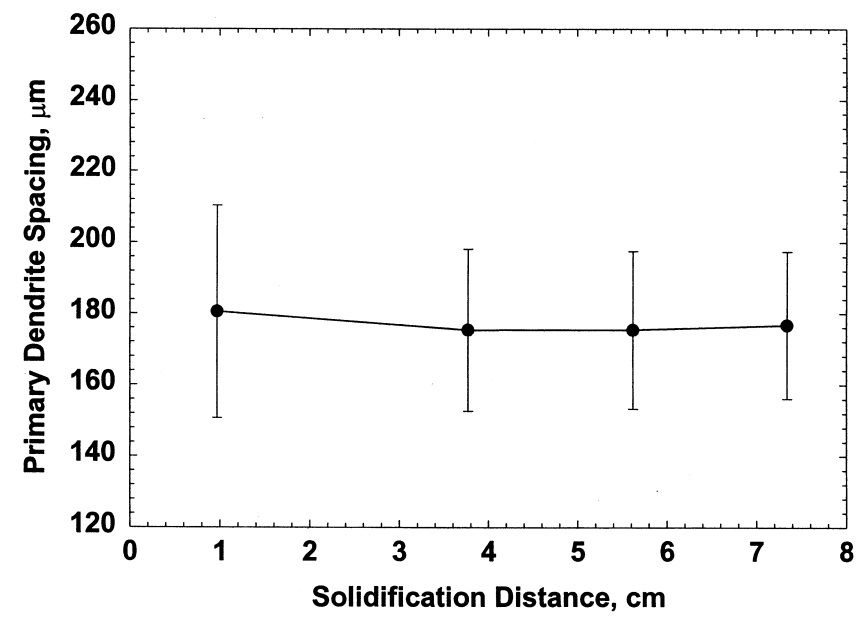

(c)

Fig. 3-Primary dendrite spacing variation as obtained from the mean MST branch length along the directionally solidified length in $(a) \mathrm{Pb}-5.8 \mathrm{wt}$ pct $\mathrm{Sb}$, $40 \mathrm{~K} \mathrm{~cm}^{-1}, 3 \mu \mathrm{m} \mathrm{s}^{-1}$; (b) Pb-5.8 wt pct Sb, $40 \mathrm{~K} \mathrm{~cm}^{-1}, 10 \mu \mathrm{m} \mathrm{s}^{-1}$; and (c) Pb-5.8 wt pct $\mathrm{Sb}, 40 \mathrm{~K} \mathrm{~cm}^{-1}, 30 \mu \mathrm{m} \mathrm{s}^{-1}$.

simulated hexagonal lattice with increasing amount of superimposed random noise. ${ }^{[9]}$ The extent of random noise has been increased at 10 pct intervals from 30 to 60 pct. With the increasing amount of superimposed noise, the $m$ value decreases and $\sigma$ increases. Even though all the $\mathrm{Pb}-\mathrm{Sb}$ alloy samples in this study were grown on [100]-oriented pure lead seeds, there was a significant variation in the ordering of the dendrites that formed at the onset of directional solidification. Therefore, any comparison of the dendrite ordering between two samples in the beginning of the directional solidification is meaningless. One can only compare the degree of ordering which occurs during directional solidification of two different samples. It is apparent that with the increasing directional solidification length, the $m-\sigma$ values move toward the direction of decreasing noise for the 10 $\mu \mathrm{m} \mathrm{s}^{-1}$ sample. However, for the sample containing the channel segregate $\left(3 \mu \mathrm{m} \mathrm{s}^{-1}\right)$, the $m-\sigma$ values remain about the same. This figure further confirms the previously discussed observation that in the absence of extensive convection, which may lead to channel segregate formation, there is a continued ordering in the distribution of primary dendrites along the directional solidification length.
3. Ordering as indicated by FT images of the dendritecenter distributions

Figure 6 shows the FT patterns along the directional solidification length of the three $\mathrm{Pb}-5.8 \mathrm{wt}$ pct $\mathrm{Sb}$ alloy samples grown at 3,10 , and $30 \mu \mathrm{m} \mathrm{s}^{-1}$ with a thermal gradient of 40 $\mathrm{K} \mathrm{cm}^{-1}$. The FT images for the $3 \mu \mathrm{m} \mathrm{s}^{-1}$ sample containing channel segregates (Figure 6(a)) show a single diffused ring throughout its directional solidification length. However, the 10 and $30 \mu \mathrm{m} \mathrm{s}^{-1}$ samples, represented in Figures 6(b) and (c), respectively, show that at the beginning of the directional solidification the pattern consists of one diffused ring. However, with the increasing length, spots begin to emerge from the circular ring pattern. Let us recall that in these FT images, the intensity (power-spectrum magnitude) corresponding to the highest frequency appears closest to the center. As mentioned earlier, one diffused ring indicates a dendrite ordering that is limited only to the nearest neighbors and has no directionality associated with it. And, the spots emerging from the circular ring pattern indicate the presence of preferred orientations in the underlying distributions of dendrites. The need for the primary dendrites to be as close to each other as possible and yet allow the preferred growth 

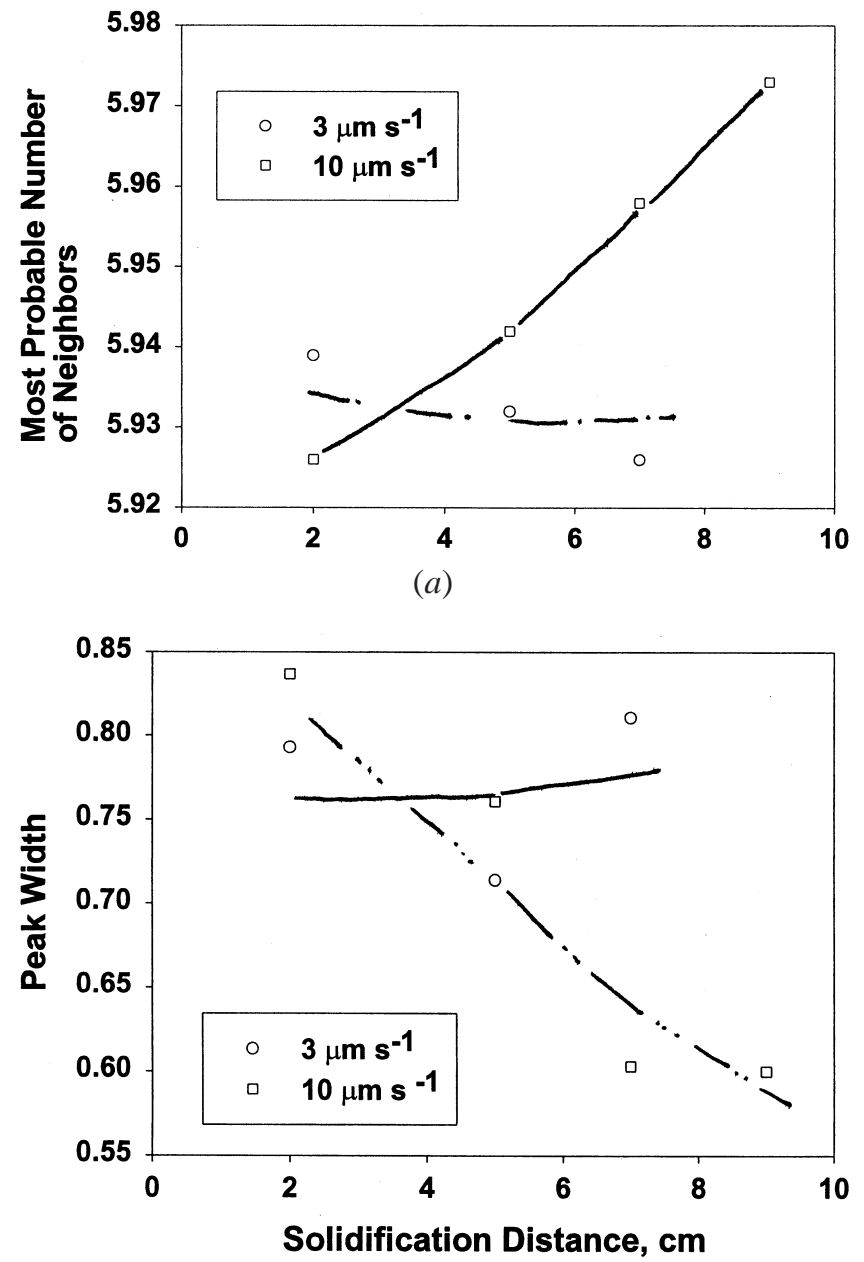

(b)

Fig. 4-Variation in relative frequency distribution of the number of nearest neighbors along the DS length in directionally solidified $\mathrm{Pb}-5.8$ wt pet $\mathrm{Sb}$ alloy grown at $40 \mathrm{~K} \mathrm{~cm}^{-1}$ : (a) growth speed $3 \mu \mathrm{m} \mathrm{s}^{-1}$ and (b) growth speed $10 \mu \mathrm{m} \mathrm{s}^{-1}$.

direction of side branches to be [100] would determine their arrangement. Such a long-range distribution would create a hexagonal arrangement of primary dendrites and yield a hexagonal FT power spectrum. However, because of the disorder introduced by the presence of subgrain boundaries and interdendritic convection, only the nearest neighbors show up in the FT.

These FT results further confirm the previous observation that even though a steady state in terms of average and median primary dendrite spacing is achieved after directionally solidifying an alloy for about three mushy zone lengths, the dendrite ordering continues through out the directional solidification length. Severe convection, as indicated by the presence of channel segregates in the $\mathrm{Pb}-5.8$ wt pct $\mathrm{Sb}$ sample grown at $40 \mathrm{~K} \mathrm{~cm}^{-1}$ and $3 \mu \mathrm{m} \mathrm{s}^{-1}$ (Figure 1(a-i)), however, does not allow this ordering to occur.

\section{E. Growth-Speed Dependence of Primary Dendrite Spacing and its Distribution during Steady-State Growth}

\section{Primary spacing range}

Figure 7 shows the growth-speed dependence of the pri-

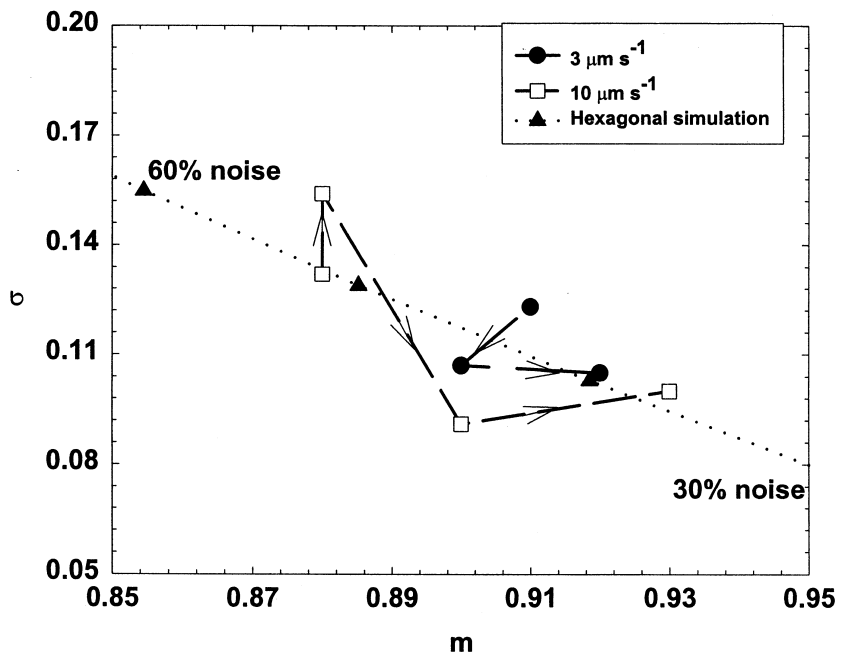

Fig. 5-Variation in the $m$ and $\sigma$ parameters along the directional solidification length for the $\mathrm{Pb}-5.8$ wt pct $\mathrm{Sb}$ samples grown at a thermal gradient of $40 \mathrm{~K} \mathrm{~cm}^{-1}$ at 3 and $10 \mu \mathrm{m} \mathrm{s}^{-1}$. The arrows correspond to the increasing directionally solidified length. The dotted straight line indicates the $m$ $\sigma$ variation for a simulated hexagonal lattice with increasing amount of superimposed random noise.

mary dendrite spacing distribution (branch-length distribution of the corresponding MSTs) in directionally solidified $\mathrm{Pb}-2.2$ wt pct $\mathrm{Sb}$ (Figure 7(b)) and $\mathrm{Pb}-5.8$ wt pct $\mathrm{Sb}$ (Figure 7(a)) alloys. The 5, 10, 25, 50, 75, 90, and 95th percentile values of MST branch length depicted in these figures are values observed after 6 to $9 \mathrm{~cm}$ of directional solidification. Therefore, they correspond to the steady-state growth. It is obvious from the figure that directional solidification of a binary alloy at a constant growth speed and thermal gradient does not produce a constant primary spacing. Instead, there exists a range of spacings, as has been suggested by recent theoretical models. ${ }^{[15,16]}$ The primary spacing decreases with increasing growth speed. It is interesting to note that the range of primary spacings decreases with the increasing growth speed for the $\mathrm{Pb}-2.2$ wt pct $\mathrm{Sb}$ alloy. However, the range for the $\mathrm{Pb}-5.8 \mathrm{wt}$ pct $\mathrm{Sb}$ alloy does not appear to depend on the growth speed.

Figure 8 plots the maximum to minimum spacing ratio, as indicated by the ratio of the 95th and 5th percentile MST branch lengths, as a function of growth speed for the two alloys. Multiple data for some growth speeds indicate results from multiple directional solidification experiments. This ratio indicates the range of the primary dendrite spacing that is stable during steady-state directional solidification. The theoretical model created by Hunt and $\mathrm{Lu}^{[15]}$ suggests this ratio to be about 2 . The ratio is only about 1.5 at the low growth speed. It increases with the increasing growth speed, approaching the value of 2 only at the highest growth speeds. The decrease in the ratio with decreasing growth speed appears to be steeper for the $\mathrm{Pb}-5.8$ wt pct $\mathrm{Sb}$ as compared with the $\mathrm{Pb}-2.2$ wt pet $\mathrm{Sb}$ alloy.

\section{Mean primary spacing}

a. A Comparison of Dendrite Spacings obtained from $\sqrt{A /(N-1)}$ and from the MST

Figure 9 plots the distribution of the ratios of the dendrite spacings obtained from $\sqrt{A /(N-1)}$ and those from the corresponding MSTs (the mean branch lengths). A compari- 


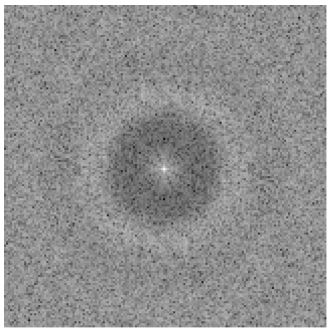

(i)

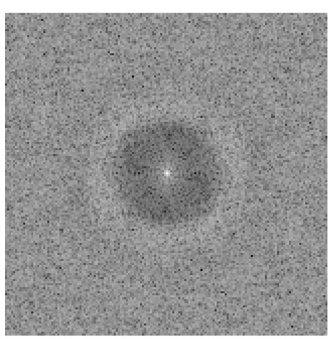

(iii)

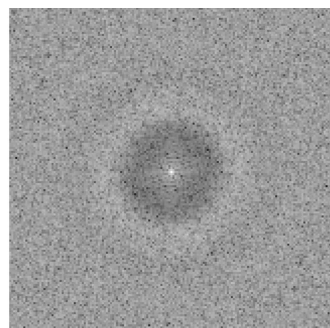

(ii)

(i)

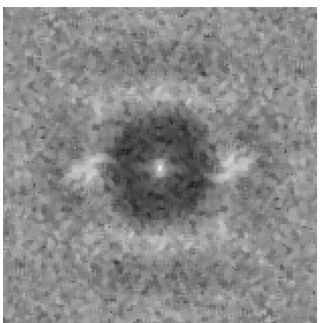

(iii)

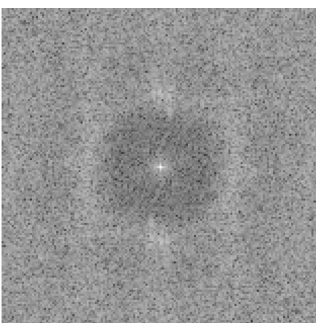

(ii)

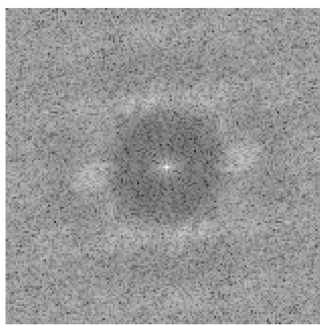

(iv)

(a)

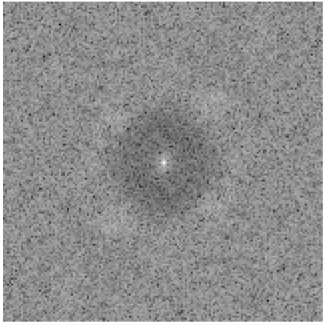

(i)

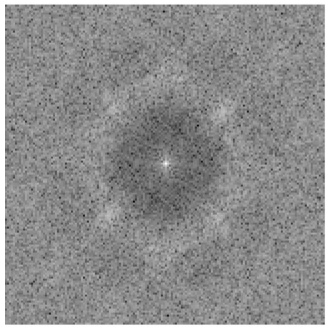

(iii)

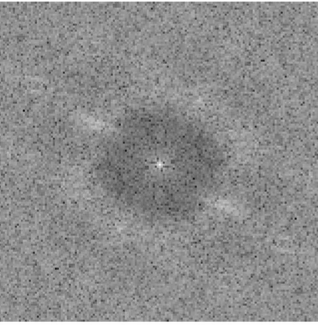

(ii)

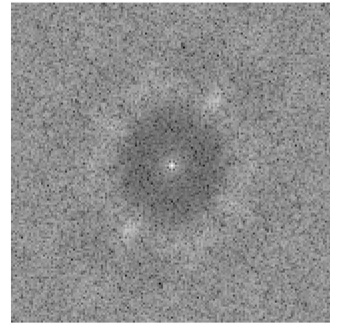

(iv)

(c)

Fig. 6-Variation in the fourier transforms of the dendrite centers along the directionally solidified length of a $\mathrm{Pb}-5.8 \mathrm{wt}$ pct $\mathrm{Sb}$ sample grown at $40 \mathrm{~K}$ $\mathrm{cm}^{-1}$. (a) Growth speed $3 \mu \mathrm{m} \mathrm{s}^{-1}$. The corresponding directionally solidified lengths are (i) $2 \mathrm{~cm}$, (ii) $5 \mathrm{~cm}$, and (iii) $7 \mathrm{~cm}$. (b) Growth speed $10 \mu \mathrm{m} \mathrm{s}$. The corresponding directionally solidified lengths are (i) $2 \mathrm{~cm}$, (ii) $5 \mathrm{~cm}$, (iii) $7 \mathrm{~cm}$, and (iv) $9 \mathrm{~cm}$. (c) Growth speed $30 \mu \mathrm{m} \mathrm{s}$. The corresponding directionally solidified lengths are (i) $2 \mathrm{~cm}$, (ii) $5 \mathrm{~cm}$, (iii) $7 \mathrm{~cm}$, and (iv) $9 \mathrm{~cm}$.

son of the two box plots shows that the results for the two alloys, $\mathrm{Pb}-2.2$ wt pet $\mathrm{Sb}$ and the $\mathrm{Pb}-5.8$ wt pct $\mathrm{Sb}$, are not statistically different from each other $(P<0.05)$. The ratio is $1.12 \pm 0.03$ for the $\mathrm{Pb}-2.2$ wt pet $\mathrm{Sb}$ alloy and $1.14 \pm$ 0.05 for the $\mathrm{Pb}-5.8$ wt pet $\mathrm{Sb}$ alloy.

\section{b. A Comparison with Theoretical Predictions}

Several theoretical models have been proposed in the literature to describe the growth-parameter dependence of primary dendrite spacings. ${ }^{[15,16]}$ We will use the model created by Hunt and $\mathrm{Lu}^{[15]}$ to compare the experimentally determined primary spacings with those predicted theoretically. Figure 10 plots the ratio of the experimentally observed mean primary spacing and those predicted theoretically as a function of growth speed for all the alloys examined in this study. The error bars correspond to a standard deviation of \pm 1 in the MST branch-length distribution. The alloy physical properties are same as those used earlier in Reference 9. Let us recall that this model considers only diffusive solutal transport and does not include convection in its analysis. It predicts the minimum stable primary dendrite spacing for a given growth condition and suggests that the maximum spacing should be about twice this minimum. The experimentally observed mean primary spacing is significantly less than the theoretical predictions. It is also interesting to note that the ratio of the experimentally observed and the theoretically predicted primary spacing decreases with decreasing growth speed, the decrease being steeper for the $\mathrm{Pb}-5.8$ wt pet Sb alloy (Figure 10(b)) as compared with $\mathrm{Pb}$ - 


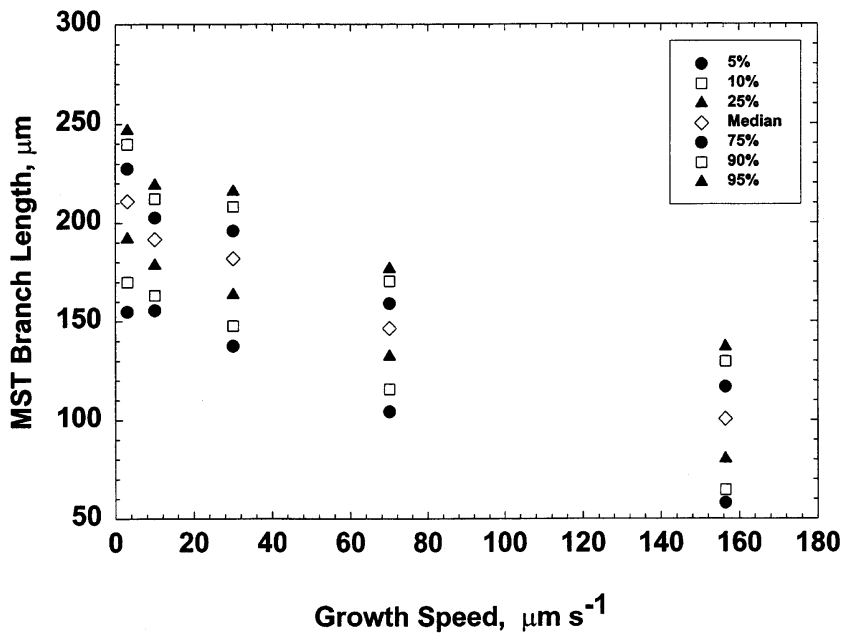

(a)

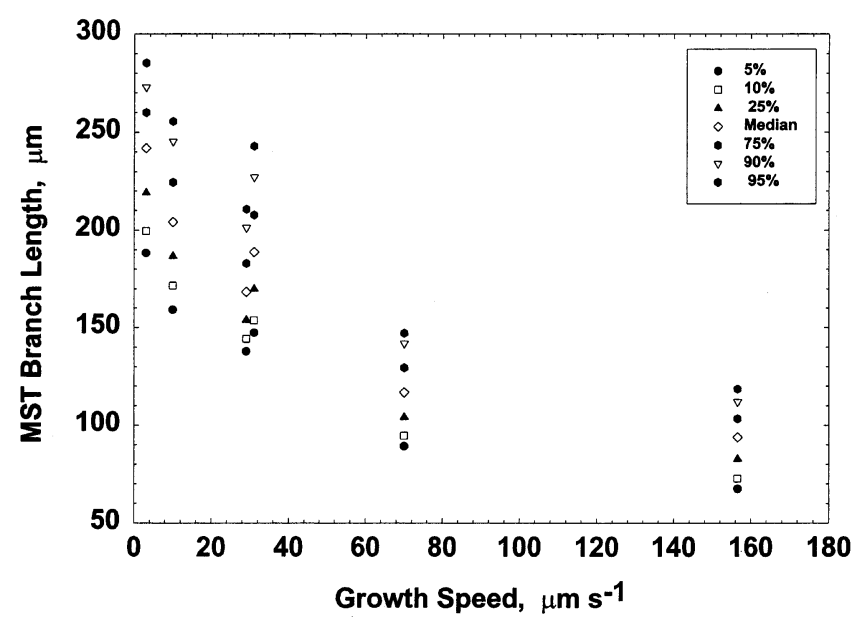

(b)

Fig. 7-Growth speed dependence of primary dendrite distribution during steady-state directional solidification of $\mathrm{Pb}-\mathrm{Sb}$ and $\mathrm{Al}-\mathrm{Cu}$ alloys: (a) $\mathrm{Pb}$ 5.8 wt pet $\mathrm{Sb}$ grown at $40 \mathrm{~K} \mathrm{~cm}^{-1}$ and $(b) \mathrm{Pb}-2.2 \mathrm{wt}$ pet $\mathrm{Sb}$ grown at 40 $\mathrm{K} \mathrm{cm}^{-1}$.

$2.2 \mathrm{wt}$ pct Sb alloy (Figure 10(a)). One may reason that the discrepancy between the theoretical predictions and the experimental observations is because of the uncertainty in the physical-property values used in the calculation, especially the solutal diffusivity and the liquid-solid surface energy, but this does not explain the systematic increase in the ratio with the decreasing growth speed. In addition, it does not explain the larger discrepancy in the Pb-5.8 wt pct $\mathrm{Sb}$ alloy as compared with that in the $\mathrm{Pb}-2.2 \mathrm{wt}$ pct $\mathrm{Sb}$. It appears that this discrepancy is due to interdendritic convection, as will be shown later.

\section{c. Dendrite distribution}

Figure 11 shows the growth-speed dependence of the $m$ $\sigma$ values obtained during steady-state directional solidification of the $\mathrm{Pb}-2.2$ wt pet $\mathrm{Sb}$ alloy. This figure also contains the $m$ and $\sigma$ values for the simulated hexagonal arrangement of points with increasing amount of superimposed random noise. Let us recall that with the increasing amount of superimposed random noise, the parameter $m$ decreases and $\sigma$ increases. The open symbols in Figure 11 correspond to the cellular-morphology samples, which were grown with a

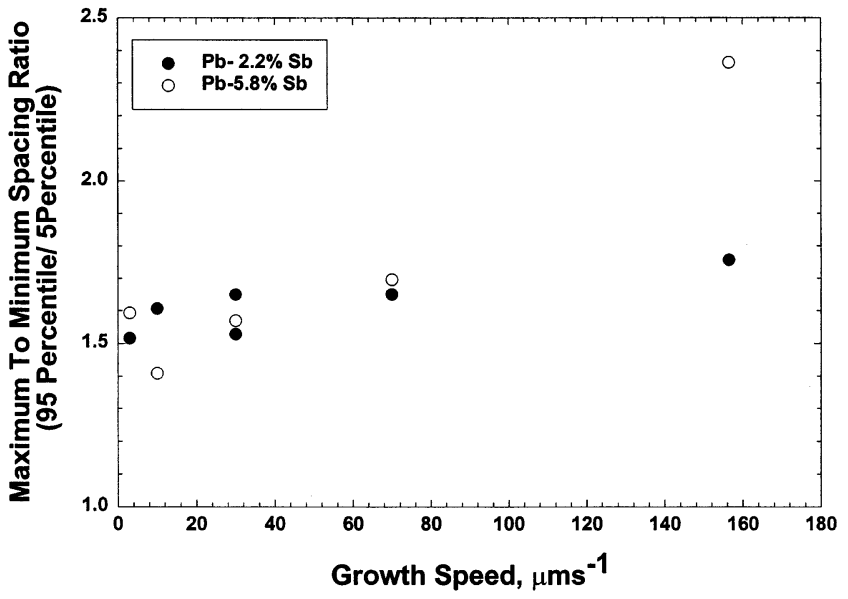

Fig. 8-Maximum to minimum MST branch length ratio in directionally solidified $\mathrm{Pb}-\mathrm{Sb}$ alloys.

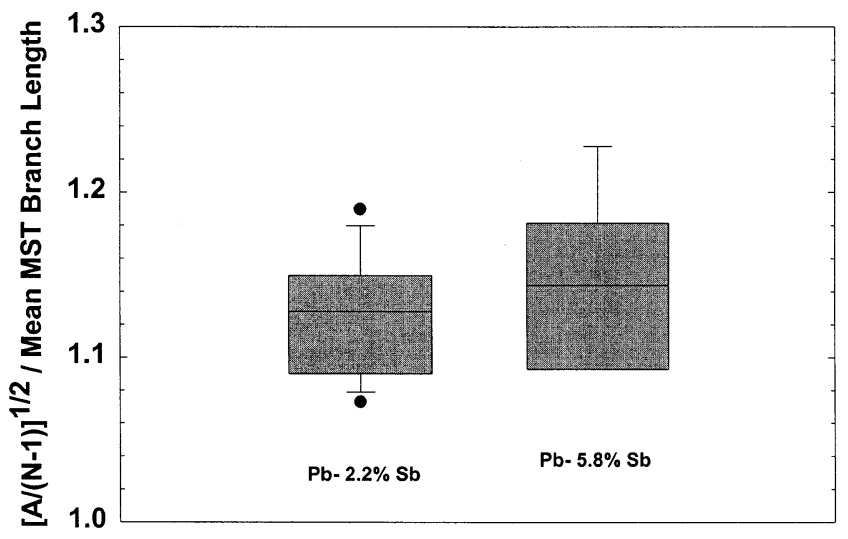

Fig. 9-Distribution of the ratios of the dendrite spacings obtained from $\sqrt{A /(\mathrm{N}-1)}$ and those from the corresponding MSTs (the mean branch lengths).

thermal gradient of $160 \mathrm{~K} \mathrm{~cm}^{-1} \cdot{ }^{[9]}$ The closed symbols are for the dendritic-morphology samples grown at $40 \mathrm{~K} \mathrm{~cm}^{-1}$. The numbers by the symbols indicate the corresponding growth speeds. For samples directionally solidified at 160 $\mathrm{K} \mathrm{cm}{ }^{-1}$, the shallow-cell, deep-cell, and cell-to-dendrite transition morphologies correspond with the growth speeds of $1.5,4$, and $5 \mu \mathrm{m} \mathrm{s}^{-1}$, respectively. At $40 \mathrm{~K} \mathrm{~cm}^{-1}$, a growth speed of $3 \mu \mathrm{m} \mathrm{s}^{-1}$ is just beyond the cell-to-dendrite transition. Therefore, this sample contained primary dendrites with barely noticeable side branches. The side branching became more prominent as the growth speed increased from 10 to $70 \mu \mathrm{m} \mathrm{s}^{-1}$. Well developed tertiary branches were observed in the sample grown at $157 \mu \mathrm{m}$ $\mathrm{s}^{-1}$. Figure 11 suggests that the cellular/dendritic array is probably most ordered in the vicinity of the cell-to-dendrite transition. The extent of disorder increases if one reduces the growth speed and moves toward the shallow-cell regime, or increases the growth speed and, thus, moves toward the well-branched dendritic morphologies.

It is interesting to note that for all the samples examined in this study, the most probable number of nearest neighbors the $\left(A_{1}\right.$ parameter in the Voronoi polygon analysis) during steady-state growth was observed to vary within a narrow range (5.96 \pm 0.02$)$, except for the $\mathrm{Pb}-5.8$ wt pct $\mathrm{Sb}$ alloy 


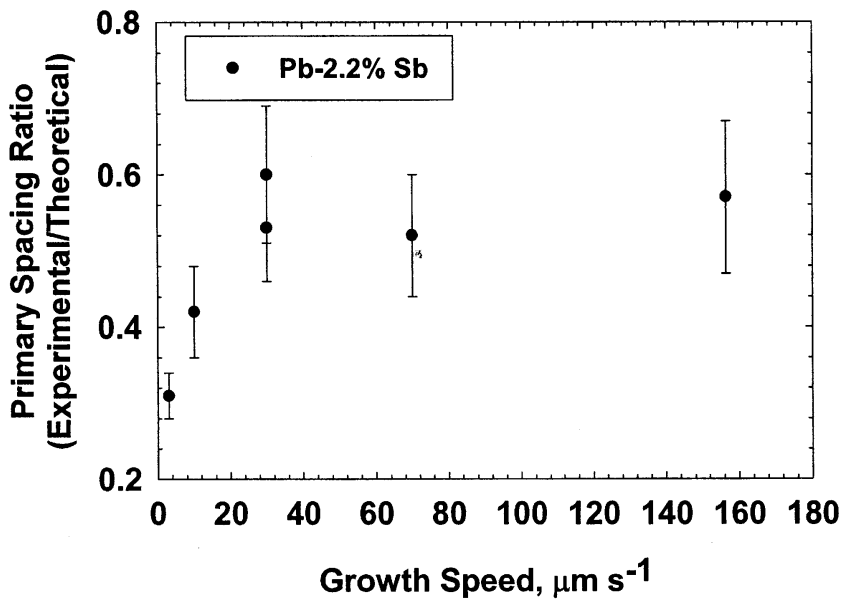

(a)

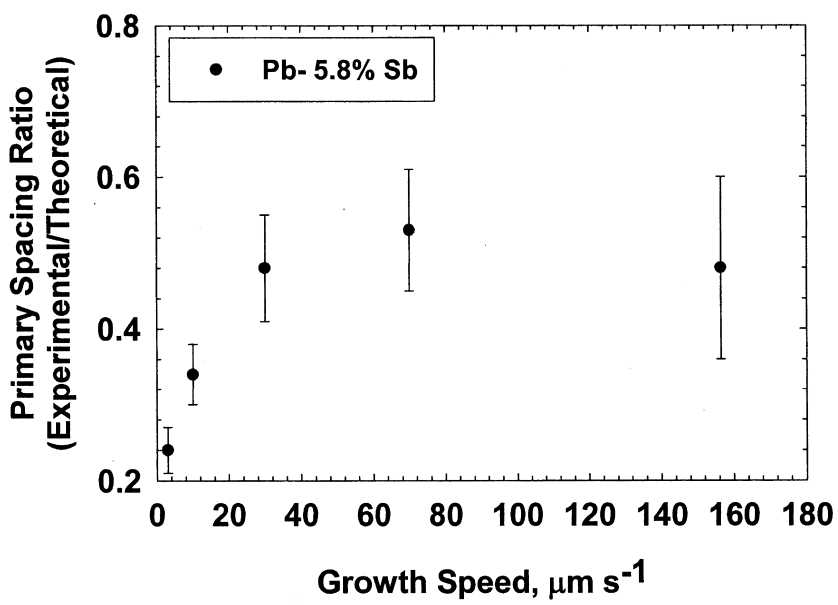

(b)

Fig. 10-Ratio of the experimentally observed mean primary spacings (mean MST branch length) and those predicted by the model due to HuntLu. ${ }^{[15]}$ The error bars denote plus-minus one standard deviation: (a) $\mathrm{Pb}$ 2.2 wt pct $\mathrm{Sb}, 40 \mathrm{~K} \mathrm{~cm}^{-1}$ and $(b) \mathrm{Pb}-5.8$ wt pet $\mathrm{Sb}, 40 \mathrm{~K} \mathrm{~cm}^{-1}$.

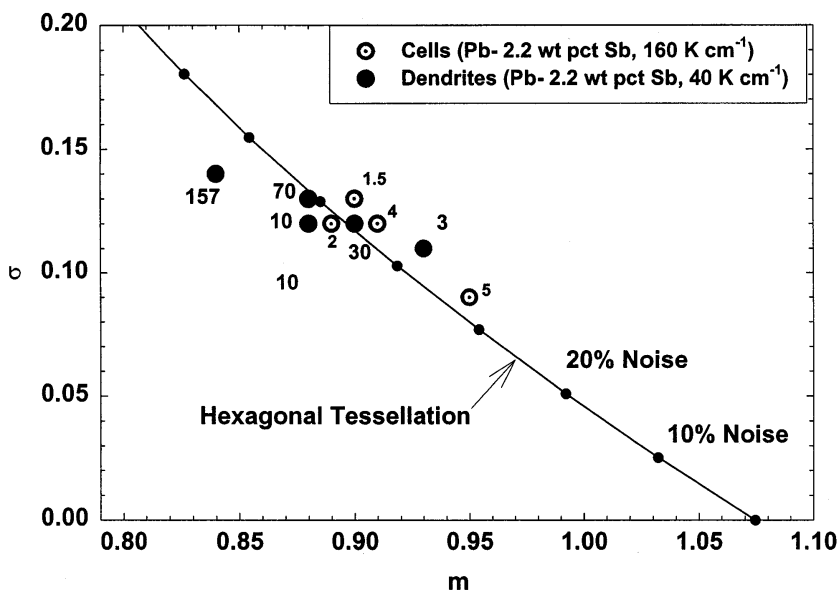

Fig. 11-Growth speed dependence of $m-\sigma$ during steady-state directional solidification of $\mathrm{Pb}-2.2$ wt pct $\mathrm{Sb}$ alloy. The open symbols correspond to the cellular morphology samples, which were grown with a thermal gradient of $160 \mathrm{~K} \mathrm{~cm}^{-1} \cdot{ }^{[9]}$ The closed symbols are for the dendritic morphology samples grown at $40 \mathrm{~K} \mathrm{~cm}^{-1}$. The numbers by the symbols indicate the corresponding growth speeds. grown at $40 \mathrm{~K} \mathrm{~cm}^{-1}$ and $3 \mu \mathrm{m} \mathrm{s}^{-1}$. The most probable number of nearest neighbors for this sample was only 5.83, indicating a higher degree of disorder as compared with the other samples.

\section{DISCUSSION}

As mentioned earlier, directional solidification of $\mathrm{Pb}-2.2$ and $5.8 \mathrm{wt}$ pet $\mathrm{Sb}$ alloys, with the melt on top and solid below, produces a melt-density profile in the mushy region which is determined by two effects: the thermal contribution provides stability against natural convection, and the solutal contribution promotes natural convection. Since the volumetric coefficient of expansion of the melt due to the increasing solutal content $\left(\beta_{c}\right), 7 \times 10^{-3}$ (wt pct Sb) ${ }^{-1}$, is several orders of magnitude larger than its thermal coefficient of expansion $\left(\beta_{t}\right), 1 \times 10^{-4} \mathrm{~K}^{-1}$, the solutal contribution dominates and is responsible for the density inversion and convection in the interdendritic melt. However, two opposing effects come into play as one moves away from the array tips into the mushy zone; the extent of the density inversion increases with the increasing distance, but the mush also becomes less permeable. Several analytica ${ }^{[18,19]}$ and numeri$\mathrm{cal}^{[12]}$ models have been proposed in the literature to relate this convection in terms of the Rayleigh number $\left(\mathrm{R}_{a}\right)$. They use different characteristic lengths (the primary dendrite spacing or the mushy zone length) and use different relationships between the mushy-zone morphology and its permeability. We will use the following definition of $\mathrm{R}_{a}^{[18]}$ to represent the extent of natural convection in the mushy zone and examine its influence on the dendritic-array morphology: $\mathrm{R}_{a}=\left(g\left(\Delta \rho / \rho_{0}\right) \kappa y\right) / \alpha v$, where $g$ is the acceleration due to gravity, $y$ is the distance from the array tip into the mushy zone, $\Delta \rho / \rho_{0}$ is the relative density inversion in the melt at $y$ with respect to that at the tip, $\kappa$ is the mean permeability averaged over the distance $y, \alpha$ is the melt thermal diffusivity $\left(1.7 \times 10^{-5} \mathrm{~m}^{2} \mathrm{~s}^{-1}\right),{ }^{[20]}$ and $v$ is the melt kinematic viscosity $\left(2.5 \times 10^{-7} \mathrm{~m}^{2} \mathrm{~s}^{-1}\right)$. Following Reference 18 , the mean permeability is related to the mean solid fraction $\left(\varepsilon_{s}\right): \kappa=6.10 \times 10^{-04} \lambda^{2}\left(1-\varepsilon_{s}\right)^{3} / \varepsilon_{s}^{2}$, where $\lambda$ is the primary dendrite spacing and $\varepsilon_{s} ;=y^{-1} \int_{0}^{y} \varepsilon_{s}(y) d y$. The $\varepsilon_{s}(y)$ value is obtained by using the Scheil equation: $\varepsilon_{s}(y)=1-\left(1-\left(y G / m_{l} C_{0}\right)\right)^{1 /(k-1)}$, where $k$ is the solute partition coefficient (0.3), $G$ is the thermal gradient, and $C_{0}$ is the solute content of the alloy. Since the interdendritic convection is localized in the immediate vicinity of the array tips, ${ }^{[12]}$ we have used $y$ values equal to 30 times the corresponding dendrite tip radii in order to calculate the corresponding $\mathrm{R}_{a}$ value. We have used the dendrite-tip radius and the $\lambda$ values calculated from the dendrite model by Hunt and $\mathrm{Lu}^{[15]}$ for calculating the $\mathrm{R}_{a}$ value.

Figure 12(a) plots $\mathrm{R}_{a}$ as a function of growth speed for the $\mathrm{Pb}-2.2$ and 5.8 wt pet $\mathrm{Sb}$ alloys grown at $40 \mathrm{~K} \mathrm{~cm}^{-1}$. It shows that the extent of interdendritic convection would increase with decreasing growth speed. Since the longitudinal macrosegregation observed in these alloys is caused by this convection, the extent of macrosegregation would be expected to increase with decreasing growth speed. This is in agreement with earlier observations. ${ }^{[10]}$ Figure 12(a) also indicates that for the same growth speed, the Pb-5.8 wt pct $\mathrm{Sb}$ alloy would have more convection than the $\mathrm{Pb}-2.2 \mathrm{wt}$ 


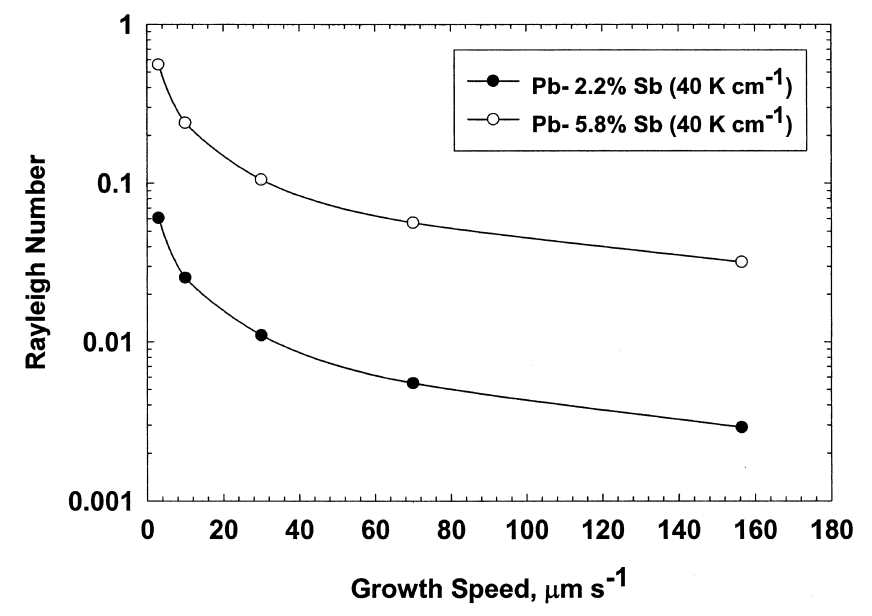

(a) MACROSEGREGATION ALONG DS LENGTH
INFLUENCE OF Sb CONTENT

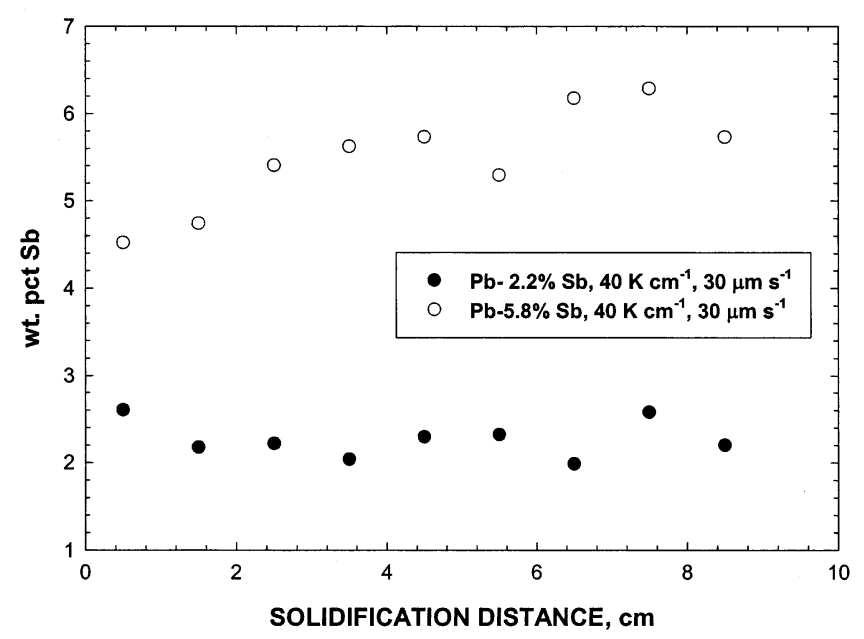

(b)

Fig. 12-Influence of convection on primary spacing and longitudinal macrosegregation in directionally solidified $\mathrm{Pb}-\mathrm{Sb}$ alloys. (a) Rayleigh number $\left(R_{a}\right)$ as a function of growth speed for the $\mathrm{Pb}-2.2$ and $5.8 \mathrm{wt}$ pct $\mathrm{Sb}$ alloys grown at $40 \mathrm{~K} \mathrm{~cm}^{-1}$. (b) Longitudinal macrosegregation in $\mathrm{Pb}-2.2$ and 5.8 wt pet $\mathrm{Sb}$ alloy samples grown at $30 \mu \mathrm{m} \mathrm{s}^{-1}$ and $40 \mathrm{~K} \mathrm{~cm}^{-1}$.

pct $\mathrm{Sb}$. For example, at $40 \mathrm{~K} \mathrm{~cm}^{-1}$ and $30 \mu \mathrm{m} \mathrm{s}^{-1}$, the $\mathrm{R}_{a}$ value for the 5.8 wt pct Sb alloy is 0.105 , as compared with 0.011 for the $2.2 \mathrm{wt}$ pct $\mathrm{Sb}$. The $5.8 \mathrm{wt}$ pct $\mathrm{Sb}$ alloy sample, therefore, shows a much larger longitudinal macrosegregation, as shown in Figure 12(b), which plots the antimony content of transverse slices machined along the directionally solidified length of samples.

The effect of convection on the primary dendrite spacing of the $\mathrm{Pb}-\mathrm{Sb}$ alloys is shown in Figure 13, which plots the earlier-discussed (Figure 10) ratio of the experimentally observed and the theoretically predicted ${ }^{[15]}$ primary spacing as a function of $\mathrm{R}_{a}$. The solid line represents a linear regression and the broken lines indicate the 95 pct confidence interval for the linear regression. The spacing ratio decreases with increasing $\mathrm{R}_{a}$ for both the $\mathrm{Pb}-\mathrm{Sb}$ alloys. This suggests a direct correlation between the decrease in the mean primary spacing and interdendritic convection. Since the Pb-5.8 wt

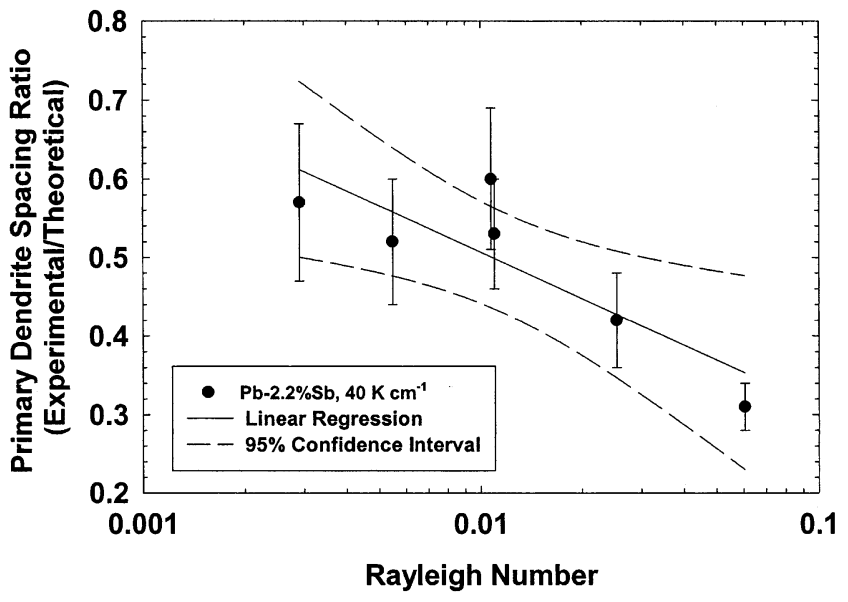

(a)

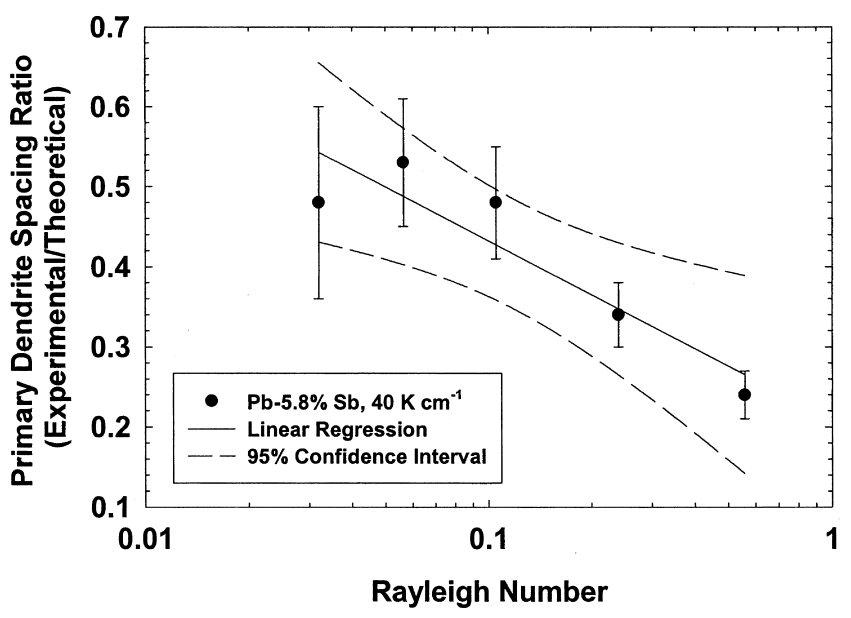

(b)

Fig. 13-Ratio of the experimentally observed and the theoretically predicted ${ }^{[15]}$ primary spacing as a function of $R_{a}$. The solid line represents a linear regression and the broken lines indicate the $95 \mathrm{pct}$ confidence interval for the linear regression: (a) $\mathrm{Pb}-2.2 \mathrm{wt}$ pct $\mathrm{Sb}$ grown at $40 \mathrm{~K} \mathrm{~cm}^{-1}$ and (b) $\mathrm{Pb}-5.8$ wt pct $\mathrm{Sb}$ grown at $40 \mathrm{~K} \mathrm{~cm}^{-1}$.

pct $\mathrm{Sb}$ alloy is more susceptible to the convection, it shows a larger decrease in the spacing as compared with the $\mathrm{Pb}$ 2.2 wt pct Sb alloy.

These observations are in agreement with results from low-gravity experiments in Al-Cu alloys, which showed that primary dendrite spacings in the sample grown in space in a convection-free environment were 2 to $4^{[21,22]}$ times larger than those in the samples grown on earth, in the presence of natural convection.

Convection not only reduces the average primary dendrite spacing, but it also affects their distribution, as indicated by Figure 14, which plots the maximum to minimum dendrite spacing ratio, i.e., the ratio of the experimentally observed 95th percentile and 5th percentile MST branch lengths (shown earlier in Figure 8), as a function of $\mathrm{R}_{a}$. This ratio indicates the range of primary dendrite spacings, which is stable during steady-state directional solidification and is expected to be about $2 .{ }^{[15]}$ The decrease in the range of primary dendrite spacings shows a reasonably good correlation with increasing $\mathrm{R}_{a}$ for the two $\mathrm{Pb}-\mathrm{Sb}$ alloys examined in this study. 
Decrease in Primary Dendrite Spacing Range due to Interdendritic Convection

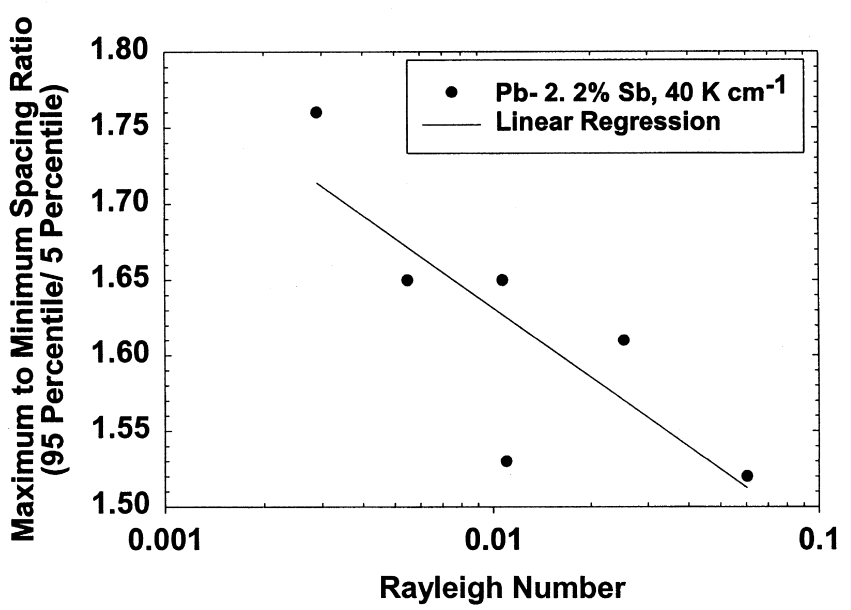

(a)

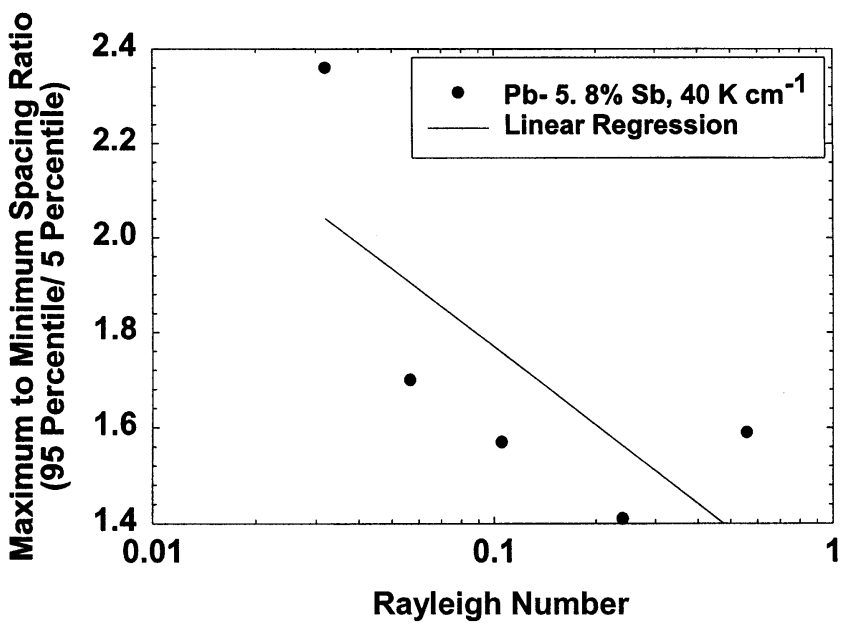

(b)

Fig. 14-Influence of convection on the maximum to minimum spacing ratio. The ratio of the experimentally observed 95 th percentile and 5th percentile MST branch lengths is plotted as a function of $R_{a}:(a) \mathrm{Pb}-2.2$ wt pet $\mathrm{Sb}$ grown at $40 \mathrm{~K} \mathrm{~cm}^{-1}$ and $(b) \mathrm{Pb}-5.8 \mathrm{wt}$ pet $\mathrm{Sb}$ grown at $40 \mathrm{~K} \mathrm{~cm}^{-1}$.

\section{SUMMARY}

A detailed statistical analysis of the primary dendrite distribution has been carried out on the transverse sections of the directionally solidified $\mathrm{Pb}-2.2$ wt pct $\mathrm{Sb}$ and $\mathrm{Pb}-5.8 \mathrm{wt}$ pct $\mathrm{Sb}$ alloy single-crystal samples, which were grown along the [100] direction at $40 \mathrm{~K} \mathrm{~cm}^{-1}$ with growth speeds varying from 3.0 to $156.5 \mu \mathrm{m} \mathrm{s}^{-1}$. The following conclusions can be drawn from this study.

1. A directional solidification distance of about three mushy zone lengths is sufficient to achieve a steady-state growth in terms of the mean primary dendrite spacing. However, local dendrite arrangement, driven by the growth of side branches along $\langle 100\rangle$, continues throughout the directional solidification process.

2. There is a dominance of six nearest neighbors in the distribution of the number of nearest-neighbor dendrites. The microstructure appears to show the greatest ordering near the cell-to-dendrite transition. The extent of disorder increases as the growth speed is decreased and the morphology becomes that of a shallow cell; it also increases as the growth speed is increased and morphology becomes more branched dendritic.

3. A range of primary dendrite spacings is present during directional solidification. The range decreases with increasing growth speed for the $\mathrm{Pb}-2.2$ wt pct $\mathrm{Sb}$ alloy. However, it appears to be constant for the $\mathrm{Pb}-5.8 \mathrm{wt}$ pct Sb.

4. Interdendritic convection during growth of the $\mathrm{Pb}-5.8 \mathrm{wt}$ pct $\mathrm{Sb}$ alloy is more intense as compared with the $\mathrm{Pb}$ $2.2 \mathrm{wt}$ pct $\mathrm{Sb}$. This results in significant longitudinal macrosegregation after directional solidification. The interdendritic convection produces (1) an increased dendrite disorder, (2) a reduced mean primary dendrite spacing, and (3) a decreased ratio of the upper and lower spacing limits, as defined by the largest 5 pct and the smallest 5 pct of the population.

\section{ACKNOWLEDGMENTS}

This research was supported by the Microgravity Materials Research Program at NASA-Marshall Space Flight Center (Huntsville, AL).

\section{REFERENCES}

1. S.H. Han and R. Trivedi: Acta Metall. Mater., 1994, vol. 42, p. 25.

2. M.A. Chopra and S.N. Tewari: Metall. Trans. A, 1991, vol. 22A, p. 2467.

3. K. Somboonsuk, J.T. Mason, and R. Trivedi: Metall. Trans., A, 1984 vol. 15A, pp. 967-75.

4. Y. Miyata, T. Suzuki, and J. Uno: Metall. Trans. A, 1985, vol. 16A, pp. 1799-1814

5. G.L. Ding, W.D. Huang, X. Huang, X. Lin, and Y.H. Zhou: Acta Mater, 1996, vol. 44 (9), pp. 3705-09.

6. S.P. O'Dell, G.L. Ding, and S.N. Tewari: Metall. Mater. Trans. A, 1999, vol. 30A, pp. 2159-65.

7. B. Billia, H. Jamgotchian, and H. Nguyen Thi: Metall. Trans. A, 1991, vol. 22A, pp. 3041-50.

8. N. Noel, H. Jamgotchian, and B. Billia: J. Cryst. Growth, 1997, vol. 181, pp. 117-32.

9. S.N. Tewari, Y-Hsuan Weng, G.L. Ding, and R. Trivedi: Metall. Mater Trans. A, 2002, vol. 33A, pp. 1229-43.

10. S.N. Ojha, G. Ding, Y. Lu, J. Reye, and S.N. Tewari: Metall. Mater Trans. A, 1999, vol. 30A, pp. 2167-71.

11. G.L. Ding and S.N. Tewari: J. Cryst. Growth, 2002, vol. 236, pp. 420-28.

12. P.K. Sung, D.R. Poirier, and S.D. Felicelli: Metall. Mater. Trans. A, 2001, vol. 202, pp. 202-07.

13. C. Dussert, G. Rasigni, M. Rasigni, J. Palmer, and A. Llebaria: Phys Rev., 1986, vol. 34B, pp. 3528-29.

14. The Visualization Toolkit, W. Schroeder, K. Martin, and B. Lorensen, Prentice-Hall PTR, Upper Saddle River, NJ, 1998, p. 398.

15. J.D. Hunt and S.Z. Lu: Metall. Mater. Trans. A, 1996, vol. 27 A, pp 611-23.

16. J.R. Sarazin and A. Hellawell: Metall. Trans. A, 1988, vol. 19A, pp. 1861-71.

17. J.A. Waren and J.S. Langer: Phys. Rev. B, 1993, vol. 47 (4), pp. 2702-12.

18. C. Beckermann, J.P. Gu, and W.J. Boettinger: Metall. Mater. Trans. A, 2000, vol. 31A, pp. 2545-52.

19. W. Yang, W. Chen, and J. deBarbadillo: Metall. Mater. Trans. A, 2001 vol. 32A, pp. 397-403.

20. M. Kucharski: Z. Metallkd., 1986, vol. 77, pp. 393-99.

21. M.D. Dupouy, D. Camel, and J.J. Favier: J. Cryst. Growth, 1993, vol. 126, pp. $480-88$.

22. J.R. Cahoon, M.C. Chaturvedi, and K.N. Tandon: Metall. Mater. Trans. A, 1998, vol. 29A, pp. 1101-09. 